OPEN ACCESS

Edited by:

Francesca Cirulli,

Istituto Superiore di Sanità, Italy

Reviewed by:

Anne-Marie Mouly,

Centre de Recherche en Neurosciences de Lyon, France

Erik B. Oleson,

University of Colorado Denver, USA

*Correspondence:

Paul B. S. Clarke paul.clarke@mcgill.ca

Received: 25 September 2015 Accepted: 18 November 2015 Published: 08 December 2015

Citation:

Scardochio T, Trujillo-Pisanty I, Conover K, Shizgal $P$ and Clarke PBS

(2015) The Effects of Electrical and

Optical Stimulation of Midbrain Dopaminergic Neurons on Rat $50-\mathrm{kHz}$ Ultrasonic Vocalizations. Front. Behav. Neurosci. 9:331 doi: 10.3389/fnbeh.2015.00331

\section{The Effects of Electrical and Optical Stimulation of Midbrain Dopaminergic Neurons on Rat 50-kHz Ultrasonic Vocalizations}

\author{
Tina Scardochio ${ }^{1}$, Ivan Trujillo-Pisanty ${ }^{2}$, Kent Conover ${ }^{2}$, Peter Shizgal ${ }^{2}$ and \\ Paul B. S. Clarke ${ }^{1,2 *}$ \\ ' Department of Pharmacology and Therapeutics, Neuropsychopharmacology, McGill University, Montreal, QC, Canada, \\ ${ }^{2}$ Department of Psychology, Center for Studies in Behavioral Neurobiology, Concordia University, Montreal, QC, Canada
}

Rationale: Adult rats emit ultrasonic vocalizations (USVs) at around $50-\mathrm{kHz}$; these commonly occur in contexts that putatively engender positive affect. While several reports indicate that dopaminergic (DAergic) transmission plays a role in the emission of $50-\mathrm{kHz}$ calls, the pharmacological evidence is mixed. Different modes of dopamine (DA) release (i.e., tonic and phasic) could potentially explain this discrepancy.

Objective: To investigate the potential role of phasic DA release in $50-\mathrm{kHz}$ call emission.

Methods: In Experiment 1, USVs were recorded in adult male rats following unexpected electrical stimulation of the medial forebrain bundle (MFB). In parallel, phasic DA release in the nucleus accumbens (NAcc) was recorded using fast-scan cyclic voltammetry. In Experiment 2, USVs were recorded following response-contingent or non-contingent optogenetic stimulation of midbrain DAergic neurons. Four 20-s schedules of optogenetic stimulation were used: fixed-interval, fixed-time, variableinterval, and variable-time.

Results: Brief electrical stimulation of the MFB increased both $50-\mathrm{kHz}$ call rate and phasic DA release in the NAcc. During optogenetic stimulation sessions, rats initially called at a high rate comparable to that observed following reinforcers such as psychostimulants. Although optogenetic stimulation maintained reinforced responding throughout the 2-h session, the call rate declined to near zero within the first $30 \mathrm{~min}$. The trill call subtype predominated following both electrical and optical stimulation.

Conclusion: The occurrence of electrically-evoked $50-\mathrm{kHz}$ calls, time-locked to phasic DA (Experiment 1), provides correlational evidence supporting a role for phasic DA in USV production. However, in Experiment 2, the temporal dissociation between calling and optogenetic stimulation of midbrain DAergic neurons suggests that phasic mesolimbic DA release is not sufficient to produce $50-\mathrm{kHz}$ calls. The emission of the trill subtype of $50-\mathrm{kHz}$ calls potentially provides a marker distinguishing positive affect from positive reinforcement.

Keywords: phasic dopamine, ultrasonic vocalizations, nucleus accumbens, midbrain dopaminergic neurons, optogenetics, fast-scan cyclic voltammetry 


\section{INTRODUCTION}

Adult rats produce two categories of ultrasonic vocalizations (USVs; Portfors, 2007; Clarke and Wright, 2015): 22-kHz (range: $20-30 \mathrm{kHz})$ and $50-\mathrm{kHz}(30-90 \mathrm{kHz})$. Calls in both categories are thought to play a role in communication (for review see: Seffer et al., 2014). In addition to their proposed communicative role, the 22- and $50-\mathrm{kHz}$ call categories appear to reflect negative and positive affective states, respectively (Knutson et al., 2002). Thus, while $22-\mathrm{kHz}$ calls are commonly associated with aversive situations (Litvin et al., 2007; Mahler et al., 2013), 50-kHz calls have been detected during a variety of rewarding events, such as rough-and-tumble play and administration of psychostimulant drugs (Burgdorf et al., 2001; Panksepp and Burgdorf, 2003; Wright et al., 2010).

Several neurotransmitters appear to play a role in the emission of 50-kHz USV s in adult rats (Fu and Brudzynski, 1994; Panksepp and Burgdorf, 2000; Wintink and Brudzynski, 2001; Fendt et al., 2006; Burgdorf et al., 2007; Arnold et al., 2010; Sadananda et al., 2012; Wright et al., 2012, 2013; Manduca et al., 2014; Wöhr et al., 2015). Here, dopamine (DA) has received particular attention, given its well-established role in motivation and reward (Bromberg-Martin et al., 2010; Ikemoto, 2010; Covey et al., 2014; Ranaldi, 2014). A variety of dopaminergic (DAergic) manipulations alter the rate at which adult rats emit $50-\mathrm{kHz}$ calls (Burgdorf et al., 2000, 2001, 2007; Williams and Undieh, 2010; Brudzynski et al., 2012; Simola et al., 2014); in particular, DAergic transmission in the nucleus accumbens (NAcc) appears both necessary and sufficient for call emission, as evidenced by studies using DA-targeted lesions and intracerebral microinjection of DAergic drugs (Burgdorf et al., 2001, 2007). Accordingly, we and others have found that both amphetamine (AMPH)induced and spontaneous $50-\mathrm{kHz}$ vocalizations are profoundly inhibited by systemically-administered D1 and D2 antagonists (Scardochio and Clarke, 2013; Wright et al., 2013; Wöhr et al., 2015). However, some DAergic drugs have produced unexpected effects after systemic administration: (1) direct DAergic agonists inhibited $50-\mathrm{kHz}$ calling across a wide dose range (Scardochio and Clarke, 2013), and (2) the DA transporter blocker GBR 12909 failed to mimic AMPH's stimulatory effect on $50-\mathrm{kHz}$ call emission, even when combined with a noradrenaline transporter blocker (Wright et al., 2013).

These apparently conflicting findings might reflect differential drug effects on two distinct modes of DA transmission: tonic and phasic. In the absence of salient stimuli, midbrain DAergic neurons display a tonic pacemaker-like activity, maintaining a stable and low DA extracellular concentration ("tone") in terminal structures such as the NAcc (Grace and Bunney, 1984). Salient stimuli such as unexpected rewards induce neuronal burst firing, resulting in phasic DA release associated with a rapid and transient increase in extracellular DA concentrations (Schultz et al., 1997; Wightman and Robinson, 2002; Redgrave et al., 2008). Several observations suggest that $50-\mathrm{kHz}$ call emission may be associated with phasic DA release. Notably, $50-\mathrm{kHz}$ vocalizations have been evoked by several manipulations that have been shown to increase phasic DA release: experimenterdelivered "tickling" (Hori et al., 2013), playback of $50-\mathrm{kHz}$ vocalizations (Willuhn et al., 2014) and the presence of a conspecific receiving reward (Kashtelyan et al., 2014). Rats will also emit $50-\mathrm{kHz}$ calls in anticipation of electrical stimulation of the medial forebrain bundle (MFB) that would be expected to increase phasic DA release in terminal areas such as the NAcc (Burgdorf et al., 2000). If phasic DA transmission promotes USV emission, this could also reconcile several pharmacological findings: (1) AMPH and cocaine reliably induced $50-\mathrm{kHz}$ calling and increased phasic DA release (Cheer et al., 2007; Wright et al., 2010, 2013; Willuhn et al., 2012; Daberkow et al., 2013; Covey et al., 2014), (2) tonic activation of postsynaptic receptors by selective DA receptor agonists inhibited spontaneous calling (Scardochio and Clarke, 2013), and (3) the DAT blocker GBR 12909, which did not increase USV emission (Wright et al., 2013), is expected to increase both tonic and phasic DA signaling (Reith et al., 1997; Budygin et al., 2000; Owesson-White et al., 2012), the former effect potentially masking the latter.

The aim of the present study was therefore to test whether phasic DA release events drive $50-\mathrm{kHz}$ calls in adult rats. Previously, Burgdorf et al. (2007) showed that electrical stimulation of the MFB evoked $50-\mathrm{kHz}$ call emission and that these calls were decreased by the DA antagonist flupenthixol. However, flupenthixol has non-DAergic effects, notably on 5HT receptors (Kühn et al., 2000), and in addition phasic DA release was inferred rather than measured. Therefore, to directly assess the involvement of phasic DA release, our first experiment asked whether electrical stimulation of the MFB would elicit USVs using parameters that evoked phasic DA release events detected using fast-scan cyclic voltammetry. The second experiment investigated whether phasic DA activity was sufficient to induce $50-\mathrm{kHz}$ calls. Here, we recorded USVs during optogenetic stimulation that was designed to selectively activate midbrain DAergic neurons. Two parameters of reinforcement were investigated: (1) expected vs. unexpected stimulation to test for anticipatory calling and (2) contingent vs. non-contingent stimulation to allow for comparison with previous studies using electrical stimulation.

\section{METHODS}

\section{Acquisition and Identification of Ultrasonic Vocalizations}

The testing procedure and acoustic analysis were in part, as previously described (Wright et al., 2010). For the initial amphetamine screen, clear Plexiglas ${ }^{\mathrm{TM}}$ experimental boxes (ENV007CT, Med Associates, St. Albans, VT) were used for testing and each was enclosed in a separate melamine compartment lined with sound attenuating acoustic foam (Primacoustic, Port Coquitlam, BC). For the optogenetic and fast-scan cyclic voltammetry (FSCV) experiments, Clear Plexiglas ${ }^{\mathrm{TM}}$ experimental boxes (optogenetic: ENV-007CT, Med Associates, St. Albans, VT, FSCV: made in-house) were also used but sound attenuating acoustic foam was not utilized. Condenser ultrasound microphones (CM16/CMPA, Avisoft Bioacoustics, Berlin, Germany) were located at the top center of each test 
box, $30-60 \mathrm{~cm}$ from the rat. Microphone signals were delivered to an UltraSoundGate $416 \mathrm{H}$ data acquisition device (Avisoft Bioacoustics, Glienicke, Germany) with a sampling rate of $250 \mathrm{kHz}$ and 16-bit resolution. Avisoft SASLab Pro software (version 5.1.14, Avisoft Bioacoustics, Berlin, Germany) was used for acoustical analysis. Spectrograms were created with a fast Fourier transform (length 512 points, overlap 75\%, FlatTop window, $100 \%$ frame size) yielding a frequency resolution of $490 \mathrm{~Hz}$ and a time resolution of $0.5 \mathrm{~ms}$. Calls were selected manually from spectrograms by an individual masked to treatment conditions. Call rate was defined as the total number of $50-\mathrm{kHz}$ calls per $5 \mathrm{~min}$, unless otherwise noted. All calls were categorized into one of 14 subtypes (see examples in Supplementary Figure 1), as defined by Wright et al. (2010), plus two additional categories that are rarely observed ( $\sim 1 \%$ of calls): "unclassifiable" (call was not loud enough, or noise was present, which prevented accurate subtyping) and "miscellaneous" (call was visible but did not clearly fit one of the 14 subtypes).

\section{Statistics}

Data were analyzed using commercial software (Systat v11, SPSS, Chicago, IL; GraphPad Software, La Jolla, CA). Except during the MFB stimulation experiment (see Section Results below), USV setween 20 - and $30-\mathrm{kHz}$ were rarely observed and were not analyzed statistically; otherwise, all USVs refer to the $50-\mathrm{kHz}$ subtype. Nonparametric tests were used when the data suggested that parametric test assumptions (e.g., variance homogeneity) were violated. Multiple vehicle conditions were compared by Friedman's nonparametric analysis of variance. Specific comparisons were performed using Wilcoxon signed-rank tests or Sign tests. For all tests, a two-tailed $p$-value $<5 \%$ was considered significant. For USV data, $n=$ number of rats and for the electrochemical data, $n=$ number of electrodes (see Section Voltammetric Data Analysis below).

\section{EXPERIMENT 1 ELECTRICAL STIMULATION OF THE MEDIAL FOREBRAIN BUNDLE AND FSCV RECORDINGS}

\section{Subjects}

Eight experimentally naïve male Long-Evans rats (Charles River Laboratories, St. Constant, Quebec, Canada) were used, weighing 359-420 g at surgery. Subjects were housed two per cage before surgery and singly-housed after surgery. Home cages were kept in a temperature- and humidity-controlled colony room $\left(20-22^{\circ} \mathrm{C}\right.$, $50-60 \%)$ with laboratory grade Sani-Chips bedding (Harlan Laboratories, Indianapolis, IN). Rats were kept on a reverse 12:12 h light/dark cycle, with lights off at $0730 \mathrm{~h}$. Behavioral testing took place between 0800 and $1300 \mathrm{~h}$. Food and water were available ad libitum, except during testing. Subjects were handled once daily for $5 \mathrm{~min}$, for 4 days prior to the first experimental day. All procedures were approved by the McGill Animal Care Committee in accordance with the guidelines of the Canadian Council on Animal Care.

\section{Electrochemical Microsensor and Reference Electrode Fabrication}

Dopamine microsensors (i.e., working electrodes) and reference electrodes for chronic implantation were fabricated as previously described (Clark et al., 2010). Briefly, a single carbon fiber (grade 34-700; Goodfellow Corporation, Caraopolis, PA, USA) was threaded through a fused silica shaft (Polymicro Technologies, Phoenix, AZ, USA) while submerged in 2-propanol. With a short length $(\sim 17 \mathrm{~mm})$ of carbon fiber protruding, two-component epoxy (Lepage Speed Set Epoxy ${ }^{\mathrm{TM}}$ ) was applied to one end and allowed to dry for 3-5h. Next, silver epoxy (MG Chemicals, Allied Electronics, Fort Worth, TX, USA) was applied to the other end of the silica shaft in order to secure electrical contact between the carbon fiber and a gold-plated PCB socket connector (Newark Element 14 \#23K7802, Chicago, IL, USA). The silver epoxy was left to dry overnight, then coated with the twocomponent epoxy. The protruding length of carbon fiber was trimmed to $150-200 \mu \mathrm{m}$.

Reference electrodes were made using silver wire (A-M systems, bare: $0.010^{\prime \prime}$, coated: $0.013^{\prime \prime}$ ) cut into lengths of $\sim 1 \mathrm{~cm}$. A small drop of silver epoxy was applied to the open end of a nickel-plated brass pin (Newark Element 14 \#82K7794, Chicago, IL, USA) and a single piece of uncoated silver wire was inserted. Once dry, the silver epoxy was covered with twocomponent epoxy and the protruding silver wire was trimmed to $\sim 3 \mathrm{~mm}$. The day before surgery, this wire was soaked in $10.2 \%$ sodium hypochlorite overnight, creating a silver/silver chloride $(\mathrm{Ag} / \mathrm{AgCl})$ surface interface.

\section{Voltammetry Surgery}

All surgical procedures followed aseptic technique. Rats were anesthetized with isoflurane (5\% induction, 2-2.5\% maintenance, AErrane, Baxter). The scalp was shaved before the rat was placed in a stereotaxic frame. Polyvinyl alcohol (1\% w/v, HypoTears, Novartis) was applied to the eyes, and a non-steroidal antiinflammatory analgesic (carprofen, $5 \mathrm{mg} / \mathrm{kg}$ ) and $0.9 \%$ sterile saline $(2 \mathrm{~mL})$ were administered subcutaneously (SC). The scalp was incised along the midline after topical application of Baxedin $^{\mathrm{TM}}$ antiseptic $(0.05 \% \mathrm{w} / \mathrm{v}$ chlorhexidine gluconate $+4 \%$ $\mathrm{v} / \mathrm{v}$ isopropyl alcohol) and local anesthetic (50:50 v/v mixture of $2 \%$ lidocaine and $0.5 \%$ bupivicaine). Skull holes were drilled and cleared of dura mater above the NAcc core $(2.0 \mathrm{~mm}$ lateral and $1.7 \mathrm{~mm}$ rostral to bregma) and shell $(0.9 \mathrm{~mm}$ lateral and $1.5 \mathrm{~mm}$ rostral to bregma); each rat received one microsensor implanted in each hemisphere (total of two microsensors per rat). Next, a skull hole was drilled in order to position the stimulating electrode (Plastics One, MS303/2-A/SP) above the medial forebrain bundle (MFB; $1.3 \mathrm{~mm}$ lateral and $4.6 \mathrm{~mm}$ caudal to bregma). Four to five additional holes were drilled at convenient locations for a reference electrode and 3-4 anchor screws. The reference electrode was lowered 3-4 $\mathrm{mm}$ from the skull surface (the entire length of silver wire) and one screw was secured to the skull; both were anchored with cranioplastic cement, leaving the stimulating electrode and microsensor holes exposed. The two microsensors were then attached to the voltammetric amplifier and lowered $(0.2 \mathrm{~mm} / \mathrm{min})$ into the target recording regions $(7.4 \mathrm{~mm}$ ventral of the brain 
surface for core and shell of NAcc). In order to determine the ideal location for placement of the stimulating electrode, the voltammetric waveform was applied at $10 \mathrm{~Hz}$ and catecholamines were monitored. Next, the stimulating electrode was lowered to $7.2 \mathrm{~mm}$ below dura mater and electrical stimulation (24 biphasic $120 \mu \mathrm{A} 60 \mathrm{~Hz}$ pulses, each pulse comprising a pair of 2 -ms phases) was applied via an optically isolated, constantcurrent stimulator (A-M Systems, Sequim, Washington). If an evoked change in catecholamine concentration was not observed at the microsensor, the stimulating electrode was lowered in $0.3 \mathrm{~mm}$ steps until electrically-evoked catecholamine efflux was detected. The electrode was then lowered in $0.1 \mathrm{~mm}$ increments until catecholamine release was maximal. This usually occurred when the stimulating electrode was 8.4 or $8.7 \mathrm{~mm}$ ventral from the brain surface. If catecholamines were not detected at this point, the stimulating electrode was lowered to and kept at $8.7 \mathrm{~mm}$. Finally, cranioplastic cement was applied to the exposed skull to secure the stimulating electrode, microsensors and the 2-3 additional screws. For post-operative pain management, subcutaneous carprofen was administered every $24 \mathrm{~h}$ for 4 days.

\section{Voltammetric Data Acquisition}

For details of hardware and software, see (Fortin et al., 2015). Waveform generation and data acquisition were carried out by using two input/output cards (NI PCI-6052E and NI PCI6711, National Instruments, Quebec, Canada) and software written in LabVIEW (National Instruments). Signals from chronically implanted microsensors were forwarded to the data acquisition system via a head-mounted voltammetric amplifier (current-to-voltage converter) and an electrical commutator (Crist Instrument Co Inc, MD, USA) mounted in a custommade Faraday cage. The voltammetric amplifier comprised an operational amplifier with a feedback resistor $\left(R_{\mathrm{f}} 5 \mathrm{M} \Omega\right)$ in parallel with a $6 \mathrm{pF}$ capacitor to exclude high frequencies. To filter out operational amplifier noise, additional capacitors bridged each of the power sources $(+15 \mathrm{~V},-15 \mathrm{~V})$ with ground. To promote a stable background current on test days, working electrodes were cycled with the voltammetric waveform at $60 \mathrm{~Hz}$ for $30 \mathrm{~min}$ and then at $10 \mathrm{~Hz}$ for $15 \mathrm{~min}$ (Moussy and Harrison, 1994). It is not uncommon to observe a $200 \mathrm{mV}$ shift in potential at reference electrodes over 2-5 days (Heien et al., 2005). This shift can be detected by the position of the Faradaic peaks within the background current. When observed, this was corrected by applying a $200 \mathrm{mV}$ offset to the waveform (Heien et al., 2005). Voltammetric recordings consisted of a series of fast voltage scans, repeated at $100 \mathrm{~ms}$ intervals (i.e., $10 \mathrm{~Hz}$ ). Each scan lasted $8.5 \mathrm{~ms}$ and comprised an ascending and descending linear $(400 \mathrm{~V} / \mathrm{s})$ sweep between 0.4 and $+1.3 \mathrm{~V}$, applied to the microsensors in relation to the $\mathrm{Ag} / \mathrm{AgCl}$ reference electrode. The potential was held at $-0.4 \mathrm{~V}$ vs. $\mathrm{Ag} / \mathrm{AgCl}$ between scans. Electrical stimulation of the MFB was used to produce phasic catecholamine release. Each stimulation train (24 biphasic pulses, each pulse comprising a pair of 2ms phases) was spaced 5-6 min apart and the following eight stimulation parameters were used: 100 and $120 \mu \mathrm{A}$ applied at $30 \mathrm{~Hz}$, and $60,80,100$, and $120 \mu \mathrm{A}$ applied at $60 \mathrm{~Hz}$. Voltammetric recordings were taken for $5 \mathrm{~s}$ before the electrical stimulation and for $10 \mathrm{~s}$ after. During this time, baseline USV recordings were taken for $55 \mathrm{~s}$ before and after each electrical stimulation.

\section{Voltammetric Data Analysis}

For the chemical identification of dopamine, current during a voltammetric scan was plotted against the applied potential and the background was subtracted (LabVIEW 7.1, National Instruments), yielding a background-subtracted cyclic voltammogram $(\mathrm{CV})$. Verification of the putative DA signals was performed using the "CV match" algorithm (Wightman et al., 1988; Heien et al., 2004; Clark et al., 2010) written in CV Analysis (LabView 7.1, National Instruments). Briefly, the background-subtracted $\mathrm{CV}$ was compared with a template voltammogram obtained from an earlier electrically-evoked (24 biphasic $120 \mu \mathrm{A} 60 \mathrm{~Hz}$ pulses, each pulse comprising a pair of 2-ms phases) in vivo recording, and a correlation coefficient was obtained. The phasic event was determined to be DAergic if the correlation coefficient was $\geq 0.75$ (Heien et al., 2003; Cheer et al., 2004). In addition, DA transients were required to meet this criterion for at least two consecutive scans. Peak DA currents at the oxidation potential of DA (approximately $0.65 \mathrm{mV}$ ) were obtained from the background-subtracted CVs. Each recording electrode (two per rat) was treated as an independent unit for the following reasons: (1) the density of DA terminals at recording sites differ (Garris et al., 1994; Peters et al., 2000), (2) DA terminals within a given brain region differ in the extent to which they are autoinhibited (Moquin and Michael, 2009), and (3) there is spatial and temporal heterogeneity of DA transmission in the ventral striatum where evoked responses are different in both amplitude and temporal profile (Wightman et al., 2007; Shu et al., 2013).

\section{Experimental Protocol Overview}

Rats were tested 1 month after surgery to allow for their recovery and the stabilization of electrodes (Polikov et al., 2005; Kozai et al., 2014). Four rats survived surgery and their head caps remained intact during the subsequent month, and were thus tested further. In vivo testing consisted of three parts: (1) Initial amphetamine screen, (2) Test day, and (3) Characterization of the voltammetric signal.

\section{Initial Amphetamine Screen}

A significant minority of rats emit few USVs in response to various stimuli (Schwarting et al., 2007). Therefore, rats underwent an initial amphetamine screen comprising three test sessions, spaced 2 days apart (Wright et al., 2010; Scardochio and Clarke, 2013). On each day, rats $(n=4)$ were placed in test chambers for 20 min immediately after an IP injection of amphetamine $(1 \mathrm{mg} / \mathrm{kg}, 1 \mathrm{~mL} / \mathrm{kg})$. Ultrasonic vocalizations emitted during the 12th, 14th, and 16th min of the third session were counted, and all four rats were assessed as high callers relative to previous data from our laboratory (see Section Results). 


\section{Test Day}

Testing resumed 20 days later. Rats were connected to the headmounted voltammetric amplifier (see Data Acquisition above) and placed in the custom made test box consisting of Clear Plexiglas $^{\mathrm{TM}}$ with laboratory grade Sani-Chips bedding. Half of the bedding was changed between each rat session. The electrical stimulation was not signaled by cues or demarcated by a specific point in time, and was thus unexpected.

\section{Characterization of in vivo Voltammetric Signals}

We confirmed the dopaminergic nature of our in vivo voltammetry signals using three main criteria: electrochemical, pharmacological and anatomical.

\section{Stimulated Release}

Activation of DAergic neurons by electrical stimulation of MFB can act as a positive control (Roitman et al., 2004). Here, stimulation of the MFB (24 biphasic pulses, each pulse comprising a pair of 2-ms phases, see Section Voltammetric Data Acquisition above for currents and frequencies) was used to detect DA release in the NAcc of each rat.

\section{Pharmacological Validation}

Pharmacological validation took place 11-20 days after test day. DA and noradrenaline are indistinguishable by FSCV (Heien et al., 2003). Therefore, to further characterize the electrochemical signal, rats $(n=3$, one rat was removed due to electrode instability) were subjected to acute tests with systemically-administered drugs. The following drugs were used: the D2/D3 agonist (-)-quinpirole hydrochloride (Sigma Aldrich, Oakville, ON), the DAT blocker GBR12909 2HCl (NIMH Chemical Synthesis and Drug Supply Program), the D2/D3 antagonist raclopride, the $\alpha 2$-adrenoreceptor antagonist yohimbine (Tocris Bioscience, Minneapolis, MN), the NET blocker desipramine hydrochloride (Sigma-RBI, St. Louis, MO) and D-amphetamine (Sigma-Aldrich, Poole, UK). Not all drugs were tested in each rat; see the Results Section and Supplementary Table 1 for details. All doses are expressed as the salt and all drugs were administered by the IP route (see Supplementary Table 2 for drug details). All drugs were dissolved in $0.9 \%$ sterile saline except for: GBR12909 in dimethyl sulfoxide (DMSO) and yohimbine in distilled water. The timing and $\mathrm{pH}$ of each control (vehicle) injection matched that of the respective drug. Drugs were administered in a volume of $1 \mathrm{~mL} / \mathrm{kg}$ except for GBR12909 $(2 \mathrm{~mL} / \mathrm{kg})$.

\section{Histological Verification of Recording Sites}

DA is the predominant electroactive neurotransmitter within the NAcc and more specifically, in the lateral core (Garris et al., 1994) and rostral shell subregions (Park et al., 2010); thus, our microsensor targeted these regions. At the end of the experiment, rats were deeply anesthetized with IP ketamine $(100 \mathrm{mg} / \mathrm{kg})$ and xylazine $(20 \mathrm{mg} / \mathrm{kg})$ and an electrolytic lesion $(+0.8 \mathrm{~mA}, 20 \mathrm{~s}$, direct current) was made to facilitate histological identification. Rats were transcardially perfused with saline and then a $10 \%$ aqueous formalin solution (Sigma, St. Louis, MO).
The brain was then removed and flash-frozen at $-50^{\circ} \mathrm{C}$ with 2 methylbutane (Acros Organics, New Jersey, USA). Brains were cut on a cryostat $\left(25-\mu \mathrm{m}\right.$ coronal sections, $\left.-20^{\circ} \mathrm{C}\right)$ and mounted on glass microscope slides. Sections were stained with cresyl violet to aid visualization of anatomical structures. When visible, the microsensor tip was localized by following the tract made by the fused-silica shaft.

\section{EXPERIMENT 2 OPTOGENETIC STIMULATION OF DAERGIC NEURONS}

\section{Subjects}

Seven heterozygote tyrosine hydroxylase $(\mathrm{TH})::$ Cre males rats (Witten et al., 2011) from Dr. Shizgal's colony were used. These rats originated from a generous donation from Dr. Karl Deisseroth (Stanford University) and Dr. Ilana Witten (Princeton University), and were subsequently outbred with Long-Evans rats (Charles River Laboratories, St. Constant, Quebec, Canada). Rats weighed 350-400 g at surgery. Subjects were singly housed in a temperature and humidity-controlled colony room (20$\left.22^{\circ} \mathrm{C}, 50-60 \%\right)$ and were kept on a reverse $12: 12 \mathrm{~h}$ light/dark cycle, with lights off at $0730 \mathrm{~h}$. Behavioral testing took place between 0800 and $1600 \mathrm{~h}$. Food and water were available ad libitum, except during testing. All procedures were carried out in accordance with the requirements of the Canadian Council on Animal Care and with the approval of the Concordia University Animal Research Ethics Committee.

\section{Rationale for Viral Construct Use}

Our optogenetic approach allowed us to selectively stimulate midbrain DA neurons to fire transiently (Tsai et al., 2009; Britt et al., 2012). We achieved neurochemical specificity by using genetically engineered rats that express Cre recombinase under the control of the tyrosine-hydroxylase promoter (Tsai et al., 2009; Witten et al., 2011). Cre-inducible viral constructs coding for channelrhoposin-2 (ChR2) were injected into the VTA (see Section Stereotaxic Virus Injections and Optical Fiber Implantation below), where cell bodies that give rise to ascending DAergic projections are located. In the genetically engineered rats employed, DA neurons express Cre and thus will express ChR2 following viral infection. Blue light was then used to activate ChR2, which leads to membrane depolarization and action-potential generation in DA neurons (see Section Optical Stimulation below). This light-driven neuronal activation produces phasic DA release in terminal regions (Bass et al., 2010; McCutcheon et al., 2014; Melchior et al., 2015).

\section{Stereotaxic Virus Injections and Optical Fiber Implantation}

Rats were first anesthetized with a solution of ketamine $(87 \mathrm{mg} / \mathrm{kg}$, Bionicle, Bellville, Ontario) and xylazine $(13 \mathrm{mg} / \mathrm{kg}$, Bayer Inc., Toronto, Ontario), given IP in a volume of $1 \mathrm{~mL} / \mathrm{kg}$, followed by atropine sulfate $(0.02-0.05 \mathrm{mg} / \mathrm{kg}, 1 \mathrm{~mL} / \mathrm{kg}, \mathrm{SC}$, Sandoz Canada Inc., Quebec) to reduce bronchial secretions. Polyvinyl alcohol (1\% w/v, "HypoTears" Novartis) was applied to the eyes, and penicillin procaine $\mathrm{G}(300000 \mathrm{IU} / \mathrm{mL}, 0.3 \mathrm{~mL}$, 
SC, Bimeda-MTC Animal Health Inc., Cambridge, Ontario) was used as a prophylactic antibiotic. Under isoflurane anesthesia (5\% $+\mathrm{O}_{2}$ for induction, $2-2.5 \%+\mathrm{O}_{2}$ for maintenance), the skull was exposed by scalpel incision and six small burr holes were drilled above target coordinates. For injections of virus [AAV-DIO-ChR2-EYFP, University of North Carolina (UNC) Vector Core facility], a 28 gauge injector was lowered into the VTA [anterior-posterior (AP) -5.4 and $-6.2 \mathrm{~mm}$; medial-lateral (ML) $\pm 0.7 \mathrm{~mm}]$ and $0.5 \mu \mathrm{L}$ of virus was infused at a rate of $0.1 \mu \mathrm{L} / \mathrm{min}$ at each of three dorsal-ventral (DV) coordinates $(-8.2,-7.7$, and $-7.2 \mathrm{~mm})$ for each of the two AP coordinates per hemisphere, for a total of 12 injections per brain. Virus was allowed to diffuse for $10 \mathrm{~min}$ between each injection. The total injection volume of virus was $6 \mu \mathrm{L}(3 \mu \mathrm{L} / \mathrm{hemisphere:}$ three DV coordinates for each of the two AP coordinates). Chronically implantable optic fibers with a $300 \mu \mathrm{m}$ core and a 0.37 numerical aperture were constructed following the methods described by Sparta et al. (2012). Optical fibers were implanted bilaterally into the VTA at a $10^{\circ}$ angle sloping laterally from the vertical (AP $-5.8 \mathrm{~mm} ; \mathrm{ML} \pm 0.7 \mathrm{~mm}$; $\mathrm{DV}-8.12$ and $-8.02 \mathrm{~mm}$ ). Skull holes were covered with Gelfoam ${ }^{\mathrm{TM}}$ (Upjohn Company of Canada, Don Mills, Ontario) and the optical implants were anchored with a combination of skull screws and dental acrylic. Animals were given the opioid analgesic buprenorphine $(0.05 \mathrm{mg} / \mathrm{kg} \mathrm{SC}, 1 \mathrm{~mL} / \mathrm{kg}$, RB Pharmaceuticals Ltd., Berkshire, UK) and returned to their home cages for recovery. Behavioral manipulations began 5-7 weeks later to allow for viral construct expression.

\section{Optical Stimulation}

The light source for the optical stimulation was a $473 \mathrm{~nm}$, $150 \mathrm{~mW}$, diode-pumped, solid-state laser (Shanghai Laser and Optics Century Company, Shanghai, China). The output of this laser was routed to the chronically implanted optical fiber via a laser-to-fiber coupler (Oz Optics, Ottawa, ON, Canada), two optical patch cords, and an optical rotary joint (Doric Lenses, Quebec, QC, Canada). A patch cord (0.22 NA, $62.5 \mathrm{um}$ core $/ 125 \mathrm{um}$ cladding, $3 \mathrm{~mm}$ reinforced jacket; AFL Global, Duncan, SC, USA) linked the output of the coupler to the rotary joint, which was mounted at the top of the test chamber; a robust, custom-built patch cord $(0.39 \mathrm{NA} ; 200 \mu \mathrm{m}$ core $/ 225 \mu \mathrm{m}$ cladding $/ 500 \mu \mathrm{m}$ buffer; Trujillo-Pisanty et al., 2015) fed the output of the rotary joint to the implanted fiber. This arrangement allowed the rat to circle freely. A pulse stimulator (A.M.P.I, Master-9, Jerusalem, Israel) was used to generate 1-s trains of $5 \mathrm{~ms}$ rectangular pulses of blue light. Each rat received optogenetic stimulation of VTA neurons through one of the implanted optical fibers; the optical probe used for stimulation (right or left) and optimal stimulation frequency were determined for each rat (see Section Optical SelfStimulation Training below). The laser was allowed to reach its most stable operating temperature for $45-120 \mathrm{~min}$ before each training or test day. Continuous optical output from the custom-built patch cord was measured daily using a power meter (Thorlabs PM100D, Newton, NJ, USA) and kept at $40 \pm 2 \mathrm{~mW}$ across sessions.

\section{Experimental Protocol}

Experiment 2 comprised the following four phases: (1) Optogenetic self-stimulation training, (2) USV screen, (3) Fixed interval training and (4) Testing on multiple schedules.

\section{Optogenetic Self-stimulation Training}

First, each rat $(n=7)$ was screened in order to optimize the optical stimulation, by determining: (1) which optical probe (i.e., left or right) was more effective behaviorally (as described next), and (2) the optimal pulse frequency, defined as the lowest optical pulse frequency that supported a maximal rate of selfstimulation. To determine the most effective probe, a successive approximation procedure was used (Peterson, 2004). Briefly, one optical implant was connected, and rats were trained to lever press on a fixed-ratio 1 schedule (FR1; one response required to receive stimulation) for unilateral delivery of 1-s trains of 5 -ms light pulses $(473 \mathrm{~mW}, 60 \mathrm{~Hz})$ into the VTA. Once the animal acquired the lever pressing behavior, two 15-min FR1 trials began. Both trials began with the lever retracted, and their extension was announced by a 10-s flashing light situated above the test box. A single depression of the extended lever triggered a stimulation train and initiated a 2-s blackout period during which the lever was retracted. The total number of lever presses during the 15-min sessions was counted. Next, the contralateral optical probe was tested the following day in the same way. The probe that supported the most pressing (i.e., most presses in a 15 min session) was considered most effective and was used for the rest of the experiment. In some rats, both probes produced similar behavioral outputs. When this happened, both optical probes were retested on a third day and the most effective one from that session was retained. Next, to determine the optimal pulse frequency, rats were permitted to lever-press for unilateral optical stimulation of the VTA, on a 2-s cumulative handling time schedule (Breton et al., 2009). In this schedule, rats earned one train of VTA stimulation (1-s duration, 5-ms light pulses) for every $2 \mathrm{~s}$ of hold-down time (i.e., a total of $2 \mathrm{~s}$ which could be accumulated over one or more presses). Each trial was announced by a 10-s flashing light. At $2 \mathrm{~s}$ before the start of the trial, a non-contingent priming stimulation was delivered which matched the pulse frequency of the contingent stimulation offered in that trial. The pulse frequency was systematically decremented across ten 2-min trials to obtain a sigmoidal response rate vs. pulse-frequency curve. The pulse frequencies varied across subjects but typically ranged from $2 \mathrm{~Hz}$ (lower asymptote) to $60 \mathrm{~Hz}$ (higher asymptote). Between two and five sessions were required to construct a reliable rate-frequency curve. The lowest pulse frequency that yielded maximal responding was considered optimal. In all subsequent testing, the pulse frequency was held at the optimal value for a given rat (pulse range: $28-59$, for details see Supplementary Table 3).

\section{USV Screen}

Near the end of optical self-stimulation training, rats were screened for USV emission in a single session. Acoustic recordings began when rats were removed from their home cage and continued for 2-5 min during optical self-stimulation 
training in their test box. As expected (Schwarting et al., 2007; Wright et al., 2010; Scardochio and Clarke, 2013), a subset of rats $(2 / 7)$ emitted few vocalizations $(<5$ calls/min) and were therefore excluded from the experiment, leaving a total of 5 experimental subjects.

\section{Fixed-Interval (FI) Training}

The rats were next trained to respond on a fixed-interval (FI) schedule. On such a schedule, the lever is armed after a fixed delay. In our implementation, the first response after the delay elapsed triggered delivery of a stimulation train and restarted timing of the delay. Training began with the delay set to $1 \mathrm{~s}$ (FI-1) and progressed until the rat performed reliably with a $20 \mathrm{~s}$ delay (FI-20). Three to 12 daily sessions, each lasting $20 \mathrm{~min}$, were run. The criterion for lengthening the delay during training was the emergence of the scalloped pattern of responding characteristic of performance on FI schedules (accelerated pressing as the end of the delay approached).

\section{Testing on Multiple Schedules}

Over the course of 8 consecutive days, each rat was tested on four different 20-s schedules of optogenetic stimulation, i.e., fixed and variable interval (FI-20, VI-20), and fixed and variable time (FT-20, VT-20). Each schedule was tested in two test sessions ( 1 session per day) lasting $2 \mathrm{~h}$. Schedules were tested in the following order: FI-20, FT-20, VI-20, and VT-20. Under the FI and FT schedules, the stimulation was expected, insofar as it was delivered (FT) or became available (FI) every $20 \mathrm{~s}$. Under VI and VT schedules, the stimulation was always unexpected, because the time between consecutive stimulations was sampled from an exponential distribution. To prevent scheduling of a subsequent reward before the optical stimulation had terminated, a fixed, $1.2 \mathrm{~s}$ lag was incorporated in the exponential distributions. Lever presses were recorded and reward delivery was programmed using software written in LabVIEW (National Instruments). Under fixed and variable interval schedules, the lever was always extended. After expiration of the minimum interval, a single lever press triggered the optical stimulation train; prior to this, lever presses were without effect. For fixed and variable time schedules, the stimulation was delivered noncontingently, and no lever was present. The interval length $(20 \mathrm{~s})$ and the test session duration $(2 \mathrm{~h})$ were selected based on previous work (Chehayeb, 2007; Ludvig et al., 2007). USVs were recorded for the whole session. No discrete cues (e.g., light or tone) were present and testing was performed in a dark room illuminated only with a red light. Since the rats virtually stopped calling within $30 \mathrm{~min}$ (see Section Results), only the first $30 \mathrm{~min}$ of calls and lever-pressing behavior were analyzed in detail.

\section{Histology}

Immunohistochemistry was performed to assess the localization of optical fibers with respect to the spread of infection; colocalization of yellow fluorescent protein (YFP) and tyrosine hydroxylase $(\mathrm{TH})$ was used to confirm the expression of the viral construct (YFP-ChR2) in DAergic neurons (TH-positive). Hence, upon completion of in vivo experiments, rats were transcardially perfused with $4 \%$ paraformaldehyde in phosphatebuffered saline (PBS). Brains were removed and post-fixed in a $4 \%$ paraformaldehyde $/ 30 \%$ sucrose solution for 2 days, and kept frozen at $-20^{\circ} \mathrm{C}$ thereafter. $40 \mu \mathrm{m}$ sections mounted on Superfrost Plus ${ }^{\mathrm{TM}}$ microscope slides (Thermo Fisher Scientific, Ottawa, Ontario), washed with PBST (phosphate buffered saline with Triton: $0.1 \mathrm{M}$ PBS $+0.3 \%$ Triton $\mathrm{X}-100)$ for $1 \mathrm{~min}(\times 3)$, and incubated with $10 \%$ normal donkey serum (Sigma Aldrich, Oakville, ON) in PBST for $30 \mathrm{~min}$, followed by a $1 \mathrm{~min}$ wash in PBS. To assess the spread and confirm the selectivity of expression of the viral construct, anti-TH and anti-GFP immunohistochemistry was performed. YFP, a variant of GFP, is readily recognized by GFP antibodies (Vashist, 2013). Slices were incubated for $48 \mathrm{~h}$ with primary antibodies diluted in $10 \%$ donkey serum-PBST solution at the following concentrations: mouse anti-GFP (1:1000, Invitrogen, \#A11120) and rabbit antiTH (1:100, Fisher, \#AB152MI). Slices were washed with PBS $(3 \times 5 \mathrm{~min})$ and incubated at room temperature for $24 \mathrm{~h}$ with the following secondary antibodies: donkey anti-mouse AlexaFluor 488 and donkey anti-rabbit AlexaFluor 594 (both 1:200, Jackson Immuno, West Grove, PA, USA). Slides were washed for 5 min $(\times 3)$, tissues were allowed to dry and then slides were coverslipped with Vectashield ${ }^{\circledR}$ mounting medium with DAPI (Vector Laboratories, Inc., Burlingame, CA, USA). Sections were subsequently imaged $(4,20$, and $60 \mathrm{X})$ on a Nikon Livescan Sweptfield confocal microscope to determine colocalization of $\mathrm{TH}$ and the ChR2-YFP construct. High magnification images were reconstructed along the $\mathrm{z}$ axis by means of the $3 \mathrm{D}$ view, image snapshot and image adjustment tools in Imaris Scientific Software (Bitplane, Concord, MA). Non-linear gamma adjustments were conducted to show detail in high magnification images.

\section{RESULTS}

\section{Experiment 1: MFB Stimulation and Rat Ultrasonic Vocalizations}

One rat was removed from all analyses because its electrical connection failed intermittently (hence, $n=3$ rats).

\section{Initial Amphetamine Screen}

The median $50-\mathrm{kHz}$ call rate on the third day of the AMPH screen was 76 calls per min (range $53-102, n=4$ rats). Based on previous studies (Wright et al., 2010; Ahrens et al., 2013; Scardochio and Clarke, 2013), all the rats would be classified as "high callers" (i.e., above-average call rate).

\section{Ultrasonic Vocalizations Following Electrical Stimulation of the MFB}

Electrical stimulation of the MFB significantly increased $50-\mathrm{kHz}$ call rate ( $n=3$ rats, Sign test, $p<0.002$, Figure 1). Calls were evoked promptly, starting $\sim 1 \mathrm{~s}$ from the start of each stimulation train (Figure 2). The main call subtypes emitted following MFB stimulation were trill, flat/trill combo and flat (Supplementary Figure 1), which accounted for 42, 27, and 13\% of all calls, respectively (Supplementary Figure 2). In one rat, more intense stimulation parameters were tested $(60 \mathrm{~Hz}, 140 \mu \mathrm{A})$, producing 


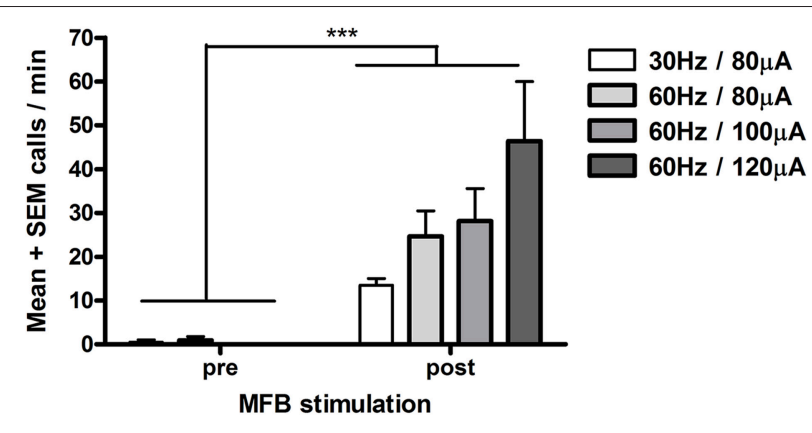

FIGURE 1 | Electrical stimulation of the medial forebrain bundle (MFB) and $\mathbf{5 0 - k H z}$ call rate (Experiment 1). Each rat $(n=3)$ was tested under each stimulation condition. Calls after MFB stimulation (post, 0-55 s following stimulation onset) were significantly greater than calls before MFB stimulation (pre, 0-55 s before stimulation). Each stimulation train was spaced 5-6 min apart. ${ }^{* *} p<0.002$ pre vs. post (Sign test, $n=12$ i.e., 4 stimulation parameters $\times 3$ rats).

$22-\mathrm{kHz}$ as well as $50-\mathrm{kHz}$ calls; therefore, these stimulation parameters were not tested with the other rats.

\section{Phasic DA Release in the Nucleus Accumbens Following Electrical Stimulation of the MFB}

Data presentation is restricted to the five electrodes confirmed to be located in the NAcc and recording phasic DA release; only one electrode was excluded (see Section Characterization of in vivo Voltammetric Signals above).

Unilateral electrical stimulation of the MFB evoked phasic dopamine release in the NAcc (Figure 2). The evoked release was bilateral ( $n=2$ rats, data not shown). Mean peak DA currents increased with increasing applied current, for both stimulation frequencies, i.e., $30 \mathrm{~Hz}$ (Wilcoxon, $p<0.05$ ) and $60 \mathrm{~Hz}$ (Friedman, $p=0.002$; Figure 3). MFB stimulation rapidly increased the call rate (Figure 2A) and the DA signal (Figure 2B), with both effects appearing within $\sim 1 \mathrm{~s}$ of stimulation onset. In contrast, the vocalization response far outlasted the transient DA signal increase. A subset of stimulations (32\% of total stimulations) produced an increase in phasic DA in the NAcc without evoking an increase in call rate (for a summary of results for each rat under each stimulation parameter, see Supplementary Table 4).

\section{Characterization of in vivo Voltammetric Signals}

\section{Electrically-evoked Release}

Following stimulation of MFB fibers, DA was detected at almost all recording sites, as revealed by background-subtracted CVs (Figures 2B,C). The exception was microsensor (i.e., electrode) $\# 2$ from rat 10, which was excluded from all analyses (thus, $n=5$ electrodes).

\section{Pharmacological Verification}

The peak DA current evoked by electrical stimulation increased significantly following an acute administration of: the indirect

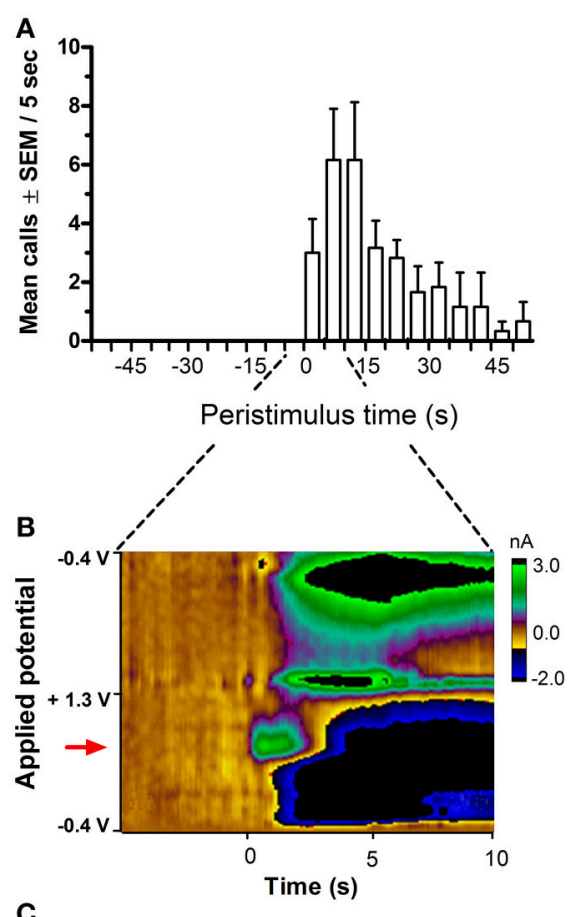

C

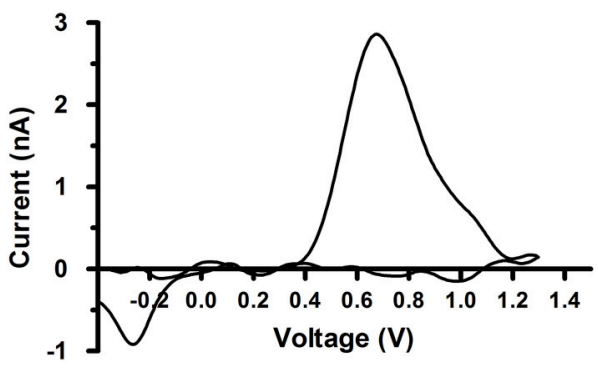

FIGURE 2 | Time course of 50-kHz call emission and phasic DA release following electrical stimulation of the medial forebrain bundle (MFB). Stimulated DA release in the nucleus accumbens (NAcC) was timed-locked to MFB stimulation (24 biphasic $120 \mu \mathrm{A} 60 \mathrm{~Hz}$ pulses, each pulse comprising a pair of 2-ms phases) and the onset of USV emission. (A) shows an increase in call rate following MFB stimulation. The 1-s stimulation started at $0 \mathrm{~s}$. (B) is a false-color plot from a representative rat, showing changes in DA current (green color) in relation to applied potential ( $y$-axis) and time ( $x$-axis), with onset of MFB stimulation occurring at $t=0 \mathrm{~s}$, at the oxidation potential of dopamine (red arrow), i.e., $\sim 0.65 \mathrm{~V}$ (vs. Ag/AgCl reference). (C) shows the corresponding background-subtracted cyclic voltammogram from the same rat at the point of peak DA current seen in (B).

DA/NA agonist amphetamine (paired $t$-test $p<0.05$ ); the D2 antagonist raclopride (paired t-test, $p<0.05$ ); and the DAT blocker GBR12909 (Supplementary Figure 3, paired $t$-test, $p<0.02$ ). The three other pharmacological conditions could not be assessed statistically because each drug was tested in a single rat; this is because two of the three rats died prematurely, one day after an injection of desipramine/yohimbine, and the other under anesthesia while its headcap was being repaired. See Supplementary Table 1 for details of completed drug conditions for each rat. 

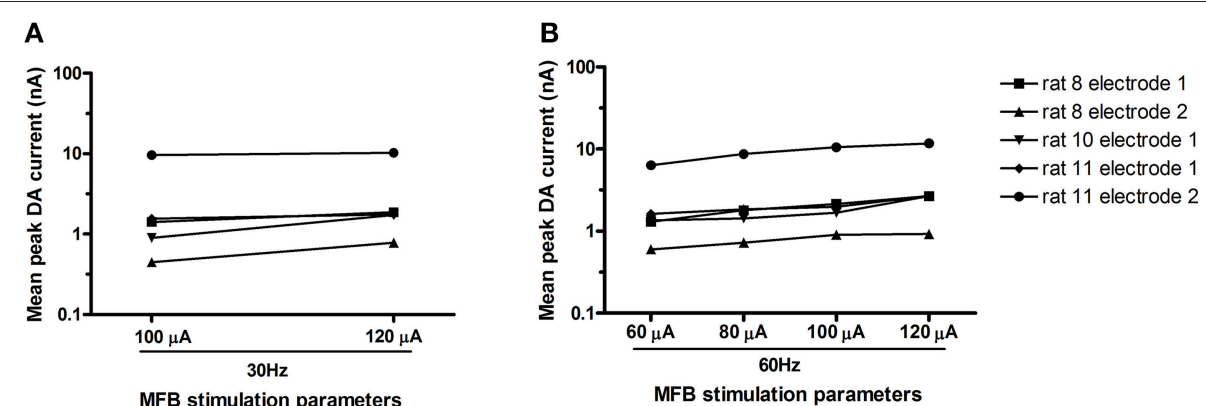

FIGURE 3 | Mean peak DA current (log) for each electrode ( $\boldsymbol{n}=\mathbf{5}$ electrodes) across various stimulation parameters. At both frequencies tested $[30 \mathrm{~Hz}-(\mathbf{A}) ; 60 \mathrm{~Hz}-(\mathbf{B})]$, peak DA current increased with current (respectively: Wilcoxon, $p<0.05$; Friedman, $p=0.002$ ).

\section{Histology}

Five electrode tips were confirmed to lie within the NAcc (Supplementary Figure 4). One electrode location could not be verified and the corresponding data are not presented; this was the same electrode ( $\# 2$ of rat 10 ) where electrically-evoked catecholamine release was not obtained.

\section{Experiment 2: Optogenetic Stimulation of Midbrain Dopaminergic Neurons}

Histological verification confirmed that the virus was confined to the VTA and the substantia nigra pars compacta (see Section Histology below for details); hence, we refer below to the targets of the optical stimulation as midbrain DAergic neurons. One of the five rats in this experiment did not emit any USVs on test days, despite having done so during the screening session, and was thus excluded from the analysis. The remaining four rats worked to obtain trains of optogenetic stimulation on both FI-20 and VI-20 test schedules. As anticipated, responding was schedule-dependent. Thus, rats pressed faster toward the end of the 20-s fixed interval, whereas they maintained a steady response rate during the variable interval when the timing of the stimulation was unpredictable (Figure 4). Within the first $30 \mathrm{~min}$ of the test session, response rates were maintained (Figures $\mathbf{5 A}, \mathbf{B}$ ) whereas calls rate steadily declined (Figures 5D-H). Over the rest of the 2-h session, lever-press rates tended to increase (Figure 5C), but $50-\mathrm{kHz}$ calling remained virtually undetectable (mean $1 \pm 0.9$ calls/min, not shown).

\section{USV Emission: Call Numbers, Categories, and Timing with Optogenetic Stimulation}

Rats called at a broadly similar rate before and after each stimulation (Figure 6). Thus, call rates occurring in the $10 \mathrm{~s}$ before or after the stimulation did not differ significantly on any of the four schedules (Wilcoxon test, NS for each schedule). However, rats called less during the 1-s train of optogenetic stimulation under all schedules except fixed time (Figure 6). Overall, call rates were significantly higher on "time" schedules than on "interval" schedules (Figure 5G, Sign test, $p<0.02$ ).

Call profiles (i.e., percentage prevalence of 14 call subtypes and two call categories) are shown in Figure 6 (insets) and Supplementary Figure 5. These profiles were comparable across the four schedules, and also between the 10-s periods before and after each stimulation (Friedman, NS). Overall, the most prevalent call subtypes were trills, flats, and flat-trills accounting for 49,15 , and 10\%, respectively (For further details see Supplementary Table 5).

\section{Assessment of Habitual Responding: Supplementary Experiment}

To test whether responding had become habitual, four additional rats were tested in extinction (Supplementary Figure 7). When the laser light source was turned off after $1 \mathrm{~h}$ of self-stimulation, subjects abruptly stopped lever pressing, and promptly resumed responding when the optical stimulation was reinstated. This experiment used more intense optogenetic stimulation parameters than in Experiment 2 (Supplementary Figure 5 legend).

\section{Histology}

Rats were sacrificed between 2 and 6 months after the last experimental test day. In all rats $(n=4)$, TH immunolabelling was considerably more intense in the VTA on the stimulated side of the brain, within approximately $170 \mu \mathrm{m}$ of the end of the optical probe (Supplementary Figure 6). This asymmetry was apparent throughout the anterior-posterior extent of the VTA/SNC in each rat.

\section{DISCUSSION}

The present study provides two main novel findings. First, unexpected electrical stimulation of the MFB elicited both phasic DA release in the NAcc (lasting $\sim 2 s$ ) and a longer-lasting increase in $50-\mathrm{kHz}$ vocalizations. Second, neurochemicallyselective optogenetic stimulation of midbrain DAergic neurons, although reinforcing, did not consistently elicit $50-\mathrm{kHz}$ calls.

\section{Electrical Stimulation of the MFB Produced Concurrent USV Emission and Phasic DA Release in the NAcc}

In Experiment 1, unexpected electrical stimulation of the MFB elicited near time-locked $50-\mathrm{kHz}$ vocalizations. In contrast, $50-$ $\mathrm{kHz}$ calling was previously reported shortly after electrical 

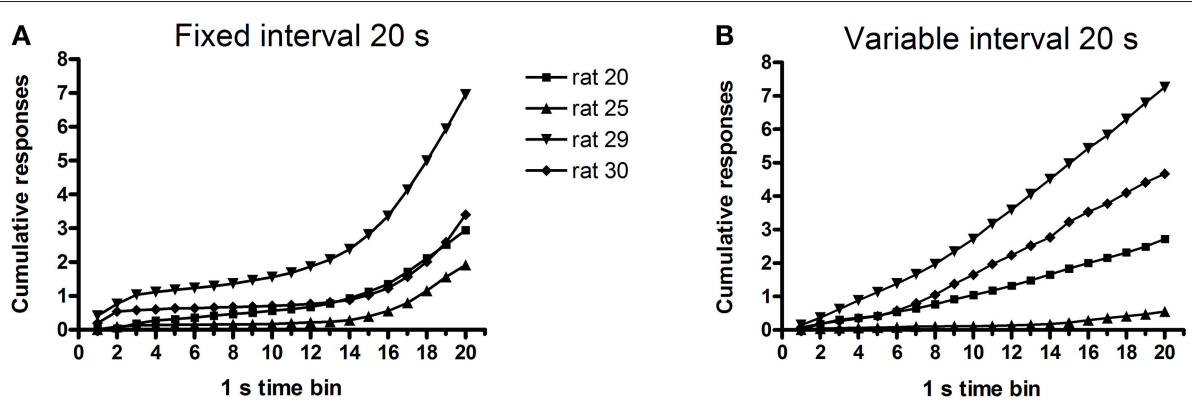

FIGURE 4 | Cumulative lever responses for each rat $(n=4)$ as a function of time since the last optogenetic stimulation. (A) shows lever responses increasing as the next stimulation opportunity approached (at 20 s). (B) shows lever pressing at a near-constant rate during the 10 s prior to the onset of the next stimulation opportunity (times randomly selected from lagged exponential distribution with mean 20 s).
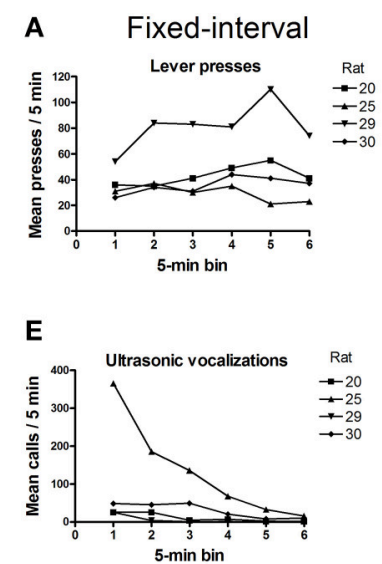
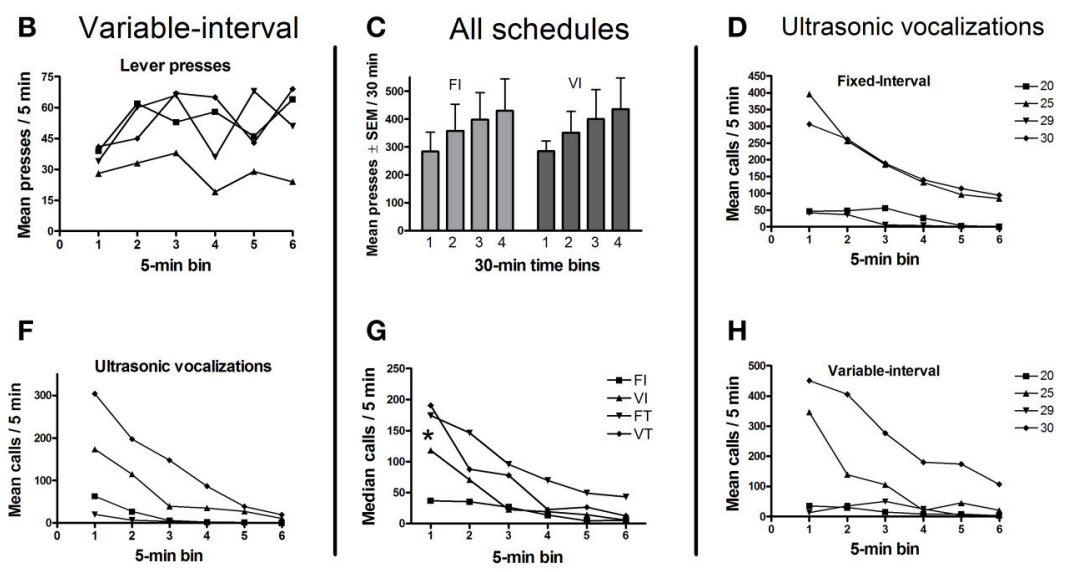

FIGURE 5 | Mean lever presses and mean calls for each schedule ( $\boldsymbol{n}=\mathbf{4}$ rats). (A,B) show that lever press rates under both schedules remained stable across successive 5-min time bins within the first 30 min of the session. (C) shows that response rates tended to increase across the 2-h session. (D-F, H) show mean calls across all four reinforcement schedules, decreasing over the first 30 min of the for each rat. (G) shows that the median call rate decreased over the first 30 min for all schedules, with rats pooled. There was also a significant increase in call number when the optogenetic stimulation was non-contingent (VT and FT schedules) vs. contingent on a lever-press (FI and VI schedules). FI, fixed interval; VI, variable interval; FT, fixed interval; VT, variable interval. All schedules are 20 s. Sign-test ${ }^{*} p<0.02$ ( $n=8$ i.e., 4 rats $\times 2$ schedules).

stimulation (Burgdorf et al., 2007), whereas in an earlier study, the same authors reported anticipatory calling $(\sim 5 \mathrm{~s}$ before stimulation) in response to non-contingent electrical stimulation (Burgdorf et al., 2000). At least two factors could contribute to the different temporal relationships between calls and stimulation trains observed here and in the two prior studies. First, Burgdorf et al. (2000) may have missed a considerable number of calls by using a heterodyne bat detector, since this device can only detect a subset of $50-\mathrm{kHz}$ calls falling within its narrow frequency band. Second, our stimulation parameters differ considerably from those used in the two earlier reports.

In earlier studies (Burgdorf et al., 2000, 2007), evoked DA release was inferred from the observed behavior (i.e., reinforced responding), whereas we have directly measured it. Here, vocalizations co-occurred with electrically-evoked phasic DA release in the NAcc, but with exceptions. Notably, during a significant minority of trials (32\%), electrical stimulation elicited phasic DA release but did not elicit any $50-\mathrm{kHz}$
USVs. During these trials, peak DA release was not noticeably lower, suggesting that calls are not simply triggered when a specific threshold of peak concentration is achieved. In this context, it is worth noting that electrical stimulation of the MFB releases many other transmitters, including 5-HT, acetylcholine, glutamate, and noradrenaline, which all appear to modulate the emission of USVs (Brudzynski and Bihari, 1990; Wintink and Brudzynski, 2001; Wright et al., 2012; Wöhr et al., 2015).

\section{Disappearance of USVs Despite Continued Optical Stimulation}

Despite continuing optogenetic stimulation of midbrain DAergic neurons, $50-\mathrm{kHz}$ calls gradually disappeared over the first $30 \mathrm{~min}$ of the 2-h session. There are several possible explanations for this divergence. A trivial explanation would be that the larynx, which generates USVs (Johnson et al., 2010), became overused and no longer capable of producing calls. However, this is 

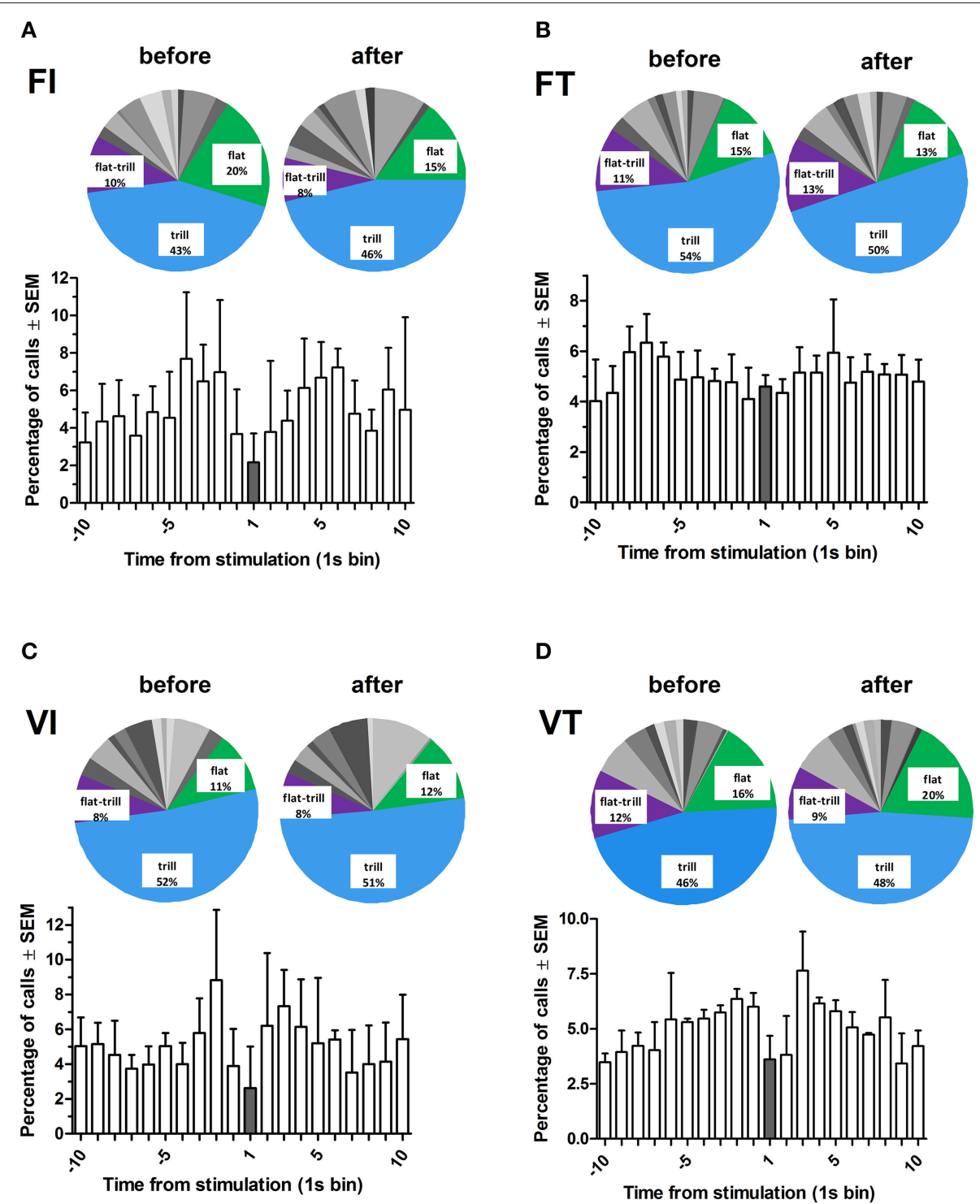

FIGURE 6 | Percentage of total calls and call subtypes under each reinforcement schedule for all rats $(n=4)$, as a function of time from stimulation. Time bin "1" represents the time at which the midbrain optogenetic stimulation occurred. Pie charts show percentages of calls (14 subtypes and 2 categories) before $(-10$ to -1$)$ and after (2-10) the stimulation. The most common calls are labeled (for details of call subtypes see Supplementary Table 5). Fl, fixed interval; FT, fixed time; VI, variable interval; VT, variable time. All schedules are $20 \mathrm{~s}$.

most unlikely since adult rats can sustain high $50-\mathrm{kHz}$ call rates (>50 calls/min) for at least an hour after acute amphetamine administration (Scardochio and Clarke, unpublished). A second possibility is that with repeated optogenetic stimulation, phasic DA transmission decreases and eventually becomes insufficient to support USV production. Three sets of observations support this notion. First, postsynaptic DA receptors may undergo desensitization, as has been observed in studies using electrical stimulation or pharmacological manipulations (Beaulieu and Gainetdinov, 2011). This appears unlikely given the persistence of optogenetic self-stimulation, a behavior which depends critically on phasic DA release (Bass et al., 2010, 2013; McCutcheon et al., 2014) and on functional D1 and D2 receptors in the
NAcc (Steinberg et al., 2013, 2014). Second, intracranial selfstimulation studies have shown that intense neuronal activation can deplete the pool of releasable DA (Garris et al., 1999; Kilpatrick et al., 2000; Park et al., 2013). While we cannot exclude the possibility that the chronic optical stimulation applied here would have depleted vesicular DA, the observed lever-pressing behavior is nonetheless consistent with DA release. A third mechanism by which DA transmission might be reduced is through desensitization of channelrhodopsin-2 following intense optogenetic stimulation (Bamann et al., 2008; Lórenz-Fonfría and Heberle, 2014). A final and related possibility that we considered is that by $30 \mathrm{~min}$ into the session, the self-stimulation behavior had become habitual and thus insensitive to the 
outcome, i.e., evoked DA release. However, the results do not support this hypothesis. Consistent with observations by Witten et al. (2011), responding was clearly dependent on whether or not it triggered the optical stimulation. The steady responding seen prior and following the disconnection of the lever (Supplementary Figure 7) further suggests that prolonged stimulation in Experiment 2 did not lose its effectiveness in activating DAergic neurons (i.e., ChR2 was not desensitized).

\section{Call Profile Following Optogenetic Stimulation of Midbrain DAergic Neurons}

Typically, $50-\mathrm{kHz}$ vocalizations are analyzed as a single group of calls or are dichotomized as frequency-modulated and flat subtypes (Portfors, 2007). However, $50-\mathrm{kHz}$ calls are far more heterogeneous, with at least 14 identifiable subtypes (Wright et al., 2010). During optogenetic stimulation sessions, the most commonly emitted call was the trill subtype. Among $50-\mathrm{kHz}$ call subtypes, it is the trill call that is preferentially suppressed by DA-depleting lesions and DA antagonist administration (Ciucci et al., 2009; Wright et al., 2013), two manipulations which would be expected to reduce both tonic and phasic DA transmission. The preponderance of trill calls in optical stimulation sessions suggests that this call subtype is promoted by phasic DA release.

Frequency-modulated calls, and trills in particular, occur in situations where positive affect putatively occurs. For example, these calls are especially abundant in the following experimental situations: (1) acute systemic administration of psychostimulants (Ahrens et al., 2009; Wright et al., 2012; Scardochio and Clarke, 2013; Simola et al., 2014), (2) anticipated delivery of food or drug delivery (Buck et al., 2014a,b; Opiol et al., 2015), (3) rough-and-tumble play (Knutson et al., 1998), and (4) sexual behavior (Snoeren and Ågmo, 2014). Since we have shown that reinforced lever pressing can be dissociated from USV emission, it appears that trill calls, insofar as they track positive affect, do so independently of positive reinforcement.

\section{Limitations Pharmacology}

In Experiment 2, several pharmacological verification tests were planned in order to confirm the neurochemical identity of the FSCV signal evoked by electrical stimulation. However, as detailed in Results, three drug tests were curtailed because of unforeseen adverse events. For example, the combination of yohimbine and desipramine appeared highly toxic, even though the same dose combination has been used previously without apparent ill effect (Park et al., 2010). Despite the restricted pharmacological testing, two additional factors indicate that our FSCV signal would have been minimally contaminated by extracellular NA: first, our recording electrodes were located in parts of the NAcc that receive little or no NA innervation (Park et al., 2010) and second, the recording electrodes used here are reportedly more sensitive to DA than NA (Clark et al., 2010).

\section{DA Release}

The hypothesis investigated in this study concerns only phasic DA release, which was measured directly in Experiment 1. Although phasic DA release during optogenetic stimulation of the VTA was not measured (in Experiment 2), it is very likely to have occurred for four main reasons. First, previous in vitro and in vivo studies have shown that optogenetic stimulation of VTA DAergic neurons reliably evokes phasic DA release in downstream targets such as the NAcc and dorsal striatum (Bass et al., 2010; Chiu et al., 2014). Second, there is minimal expression of ChR2 in neurons lacking tyrosine hydroxylase (Witten et al., 2011). Third, our histological verification confirms that the viral transfection was restricted to neurons that express tyrosine hydroxylase. Fourth, our preliminary recordings (Cossette et al., 2014) have confirmed that phasic DA release occurs in the NAcc following optogenetic stimulation of the VTA, using identical stimulation parameters.

\section{Optogenetic Test Day Order}

In Experiment 2, the reinforcement schedules were tested in a fixed order, as follows: fixed-interval, fixed-time, variableinterval, and variable-time. This particular sequence was chosen so as to limit the number of training sessions after the acquisition of FR1 responding. Testing order, however, would not have acted as a significant confounder given that all four schedules dissociated persistent lever-pressing behavior from declining USV emission.

\section{CONCLUSION}

We have confirmed that immediately following electrical stimulation of the MFB, rats start to emit $50-\mathrm{kHz}$ calls. The onset of these vocalizations coincided with phasic DA release in the NAcc. Optical stimulation of midbrain DAergic neurons was initially associated with high $50-\mathrm{kHz}$ call rates and a trillrich call profile, as occurs after systemic administration of psychostimulants. However, because optogenetic stimulation of midbrain DAergic neurons did not produce sustained calling, experimentally-induced phasic DA release in the NAcc does not appear a sufficient stimulus to induce $50-\mathrm{kHz}$ call emission.

\section{AUTHOR CONTRIBUTIONS}

TS: Contributed to the conception and design of the work. Acquired and analyzed all data for Experiment 1. Acquired and analyzed the data for Experiment 2: USV screen, FI training, and testing on multiple schedules. Drafted and critically reviewed intellectual content. Submitted a final approval of the version to be published and is accountable for all aspects of the work. IT: Contributed to the conception and design of the work. Acquired and analyzed the data for Experiment 2: optogenetic surgeries, optical self-stimulation training, USV screen, training, and supervision on test days and histology. Critically reviewed and contributed to intellectual content. Submitted a final approval of the version to be published and is accountable for all aspects of the work. KC: Contributed to the content and analyzed data for Figure 4. Critically reviewed intellectual content. Submitted a final approval of the version to be published and is accountable for all aspects of the work. PS: Contributed to the conception and design of Experiment 2. Critically reviewed and contributed to intellectual content. Submitted a final approval of the version to 
be published and is accountable for all aspects of the work. PC: Contributed to the conception and design of both experiments. Drafted and critically reviewed intellectual content. Submitted a final approval of the version to be published and is accountable for all aspects of the work.

\section{ACKNOWLEDGMENTS}

The (TH)::Cre rat colony originated from a generous donation from Dr. Karl Deisseroth (Stanford University) and Dr. Ilana Witten (Princeton University). We would like to thank MariePierre Cossette for contributing data to Supplementary Figure 7 and for her thoughtful scientific discussions. Studies were supported by: Natural Science and Engineering Research Council of Canada (NSERC) Discovery Grant (155055, to PC and RGPIN 308-11 to PS), Canadian Institutes of Health Research of Canada (MOP-10516 to PC), Fonds

\section{REFERENCES}

Ahrens, A. M., Ma, S. T., Maier, E. Y., Duvauchelle, C. L., and Schallert, T. (2009). Repeated intravenous amphetamine exposure: rapid and persistent sensitization of $50-\mathrm{kHz}$ ultrasonic trill calls in rats. Behav. Brain Res. 197, 205-209. doi: 10.1016/j.bbr.2008.08.037

Ahrens, A. M., Nobile, C. W., Page, L. E., Maier, E. Y., Duvauchelle, C. L., and Schallert, T. (2013). Individual differences in the conditioned and unconditioned rat $50-\mathrm{kHz}$ ultrasonic vocalizations elicited by repeated amphetamine exposure. Psychopharmacology (Berl) 229, 687-700. doi: 10.1007/s00213-013-3130-9

Arnold, J. C., Dielenberg, R. A., and McGregor, I. S. (2010). Cannabinoids increase conditioned ultrasonic vocalisations and cat odour avoidance in rats: strain differences in drug-induced anxiety. Life Sci. 87, 572-578. doi: 10.1016/j.lfs.2010.09.018

Bamann, C., Kirsch, T., Nagel, G., and Bamberg, E. (2008). Spectral characteristics of the photocycle of channelrhodopsin-2 and its implication for channel function. J. Mol. Biol. 375, 686-694. doi: 10.1016/j.jmb.2007.10.072

Bass, C. E., Grinevich, V. P., Kulikova, A. D., Bonin, K. D., and Budygin, E. A. (2013). Terminal effects of optogenetic stimulation on dopamine dynamics in rat striatum. J. Neurosci. Methods 214, 149-155. doi: 10.1016/j.jneumeth.2013.01.024

Bass, C. E., Grinevich, V. P., Vance, Z. B., Sullivan, R. P., Bonin, K. D., and Budygin, E. A. (2010). Optogenetic control of striatal dopamine release in rats. J. Neurochem. 114, 1344-1352. doi: 10.1111/j.1471-4159.2010.06850.x

Beaulieu, J. M., and Gainetdinov, R. R. (2011). The physiology, signaling, and pharmacology of dopamine receptors. Pharmacol. Rev. 63, 182-217. doi: $10.1124 /$ pr.110.002642

Breton, Y. A., Marcus, J. C., and Shizgal, P. (2009). Rattus psychologicus: construction of preferences by self-stimulating rats. Behav. Brain Res. 202, 77-91. doi: 10.1016/j.bbr.2009.03.019

Britt, J. P., Benaliouad, F., McDevitt, R. A., Stuber, G. D., Wise, R. A., and Bonci, A. (2012). Synaptic and behavioral profile of multiple glutamatergic inputs to the nucleus accumbens. Neuron 76, 790-803. doi: 10.1016/j.neuron.2012.09.040

Bromberg-Martin, E. S., Matsumoto, M., and Hikosaka, O. (2010). Dopamine in motivational control: rewarding, aversive, and alerting. Neuron 68, 815-834. doi: 10.1016/j.neuron.2010.11.022

Brudzynski, S. M., and Bihari, F. (1990). Ultrasonic vocalization in rats produced by cholinergic stimulation of the brain. Neurosci. Lett. 109, 222-226. doi: 10.1016/0304-3940(90)90567-S

Brudzynski, S. M., Komadoski, M., and St Pierre, J. (2012). Quinpirole-induced $50 \mathrm{kHz}$ ultrasonic vocalization in the rat: role of D2 and D3 dopamine receptors. Behav. Brain Res. 226, 511-518. doi: 10.1016/j.bbr.2011.10.004

Buck, C. L., Malavar, J. C., George, O., Koob, G. F., and Vendruscolo, L. F. (2014a). Anticipatory $50 \mathrm{kHz}$ ultrasonic vocalizations are associated with de Recherche Santé du Québec (to Groupe de recherche en neurobiologie comportementale), Concordia University Research Chair grant (to PS), Concordia University Facilities Optimization grant (to PS and Dr. Nadia Chaudhuri), a Fonds de recherche Nature et Technologies Doctoral Research Scholarship (to TS), a Fonds de recherche Santé Doctoral Training Award and a scholarship from "Consejo Nacional de Ciencia y Tecnologia" (to IT). The authors have no financial relationship with the organizations that sponsored this research. All experiments comply with the current laws of Canada.

\section{SUPPLEMENTARY MATERIAL}

The Supplementary Material for this article can be found online at: http://journal.frontiersin.org/article/10.3389/fnbeh. 2015.00331

escalated alcohol intake in dependent rats. Behav. Brain Res. 271, 171-176. doi: 10.1016/j.bbr.2014.06.003

Buck, C. L., Vendruscolo, L. F., Koob, G. F., and George, O. (2014b). Dopamine D1 and mu-opioid receptor antagonism blocks anticipatory $50 \mathrm{kHz}$ ultrasonic vocalizations induced by palatable food cues in Wistar rats. Psychopharmacology (Berl) 231, 929-937. doi: 10.1007/s00213-013-3307-2

Budygin, E. A., Kilpatrick, M. R., Gainetdinov, R. R., and Wightman, R. M. (2000). Correlation between behavior and extracellular dopamine levels in rat striatum: comparison of microdialysis and fast-scan cyclic voltammetry. Neurosci. Lett. 281, 9-12. doi: 10.1016/S0304-3940(00)00813-2

Burgdorf, J., Knutson, B., and Panksepp, J. (2000). Anticipation of rewarding electrical brain stimulation evokes ultrasonic vocalization in rats. Behav. Neurosci. 114, 320-327. doi: 10.1037/0735-7044.114.2.320

Burgdorf, J., Knutson, B., Panksepp, J., and Ikemoto, S. (2001). Nucleus accumbens amphetamine microinjections unconditionally elicit 50$\mathrm{kHz}$ ultrasonic vocalizations in rats. Behav. Neurosci. 115, 940-944. doi: 10.1037/0735-7044.115.4.940

Burgdorf, J., Wood, P. L., Kroes, R. A., Moskal, J. R., and Panksepp, J. (2007). Neurobiology of $50-\mathrm{kHz}$ ultrasonic vocalizations in rats: electrode mapping, lesion, and pharmacology studies. Behav. Brain Res. 182, 274-283. doi: 10.1016/j.bbr.2007.03.010

Cheer, J. F., Wassum, K. M., Heien, M. L., Phillips, P. E., and Wightman, R. M. (2004). Cannabinoids enhance subsecond dopamine release in the nucleus accumbens of awake rats. J. Neurosci. 24, 4393-4400. doi: 10.1523/JNEUROSCI.0529-04.2004

Cheer, J. F., Wassum, K. M., Sombers, L. A., Heien, M. L., Ariansen, J. L., Aragona, B. J., et al. (2007). Phasic dopamine release evoked by abused substances requires cannabinoid receptor activation. J. Neurosci. 27, 791-795. doi: 10.1523/JNEUROSCI.4152-06.2007

Chehayeb, D. (2007). Factors Affecting Amphetamine-Induced $50 \mathrm{kHz}$ Ultrasonic Vocalizations in Adult Rats. Master thesis, McGill University.

Chiu, W. T., Lin, C. M., Tsai, T. C., Wu, C. W., Tsai, C. L., Lin, S. H., et al. (2014). Real-time electrochemical recording of dopamine release under optogenetic stimulation. PLoS ONE 9:e89293. doi: 10.1371/journal.pone.0089293

Ciucci, M. R., Ahrens, A. M., Ma, S. T., Kane, J. R., Windham, E. B., Woodlee, M. T., et al. (2009). Reduction of dopamine synaptic activity: degradation of $50-\mathrm{kHz}$ ultrasonic vocalization in rats. Behav. Neurosci. 123, 328-336. doi: $10.1037 / \mathrm{a} 0014593$

Clark, J. J., Sandberg, S. G., Wanat, M. J., Gan, J. O., Horne, E. A., Hart, A S., et al. (2010). Chronic microsensors for longitudinal, subsecond dopamine detection in behaving animals. Nat. Methods 7, 126-129. doi: 10.1038/nmeth. 1412

Clarke, P. B., and Wright, J. M. (2015). "Ultrasonic vocalizations," in Encyclopedia of Psychopharmacology, eds I. Stolerman and L. H. Price (Berlin; Heidelberg: Springer), 1765-1771. doi: 10.1007/978-3-642-36172-2_7022 
Cossette, M.-P., Trujillo-Pisanty, I., Witten, I. B., Deisseroth, K., and Shizgal, P. (2014). Optogenetic excitation of midbrain dopamine neurons and an afferent pathway: implications of electrochemical and behavioral sequelae for the descending-path hypothesis. 755.01. [Abstract] Soc. Neurosci. 2014.

Covey, D. P., Roitman, M. F., and Garris, P. A. (2014). Illicit dopamine transients: reconciling actions of abused drugs. Trends Neurosci. 37, 200-210. doi: 10.1016/j.tins.2014.02.002

Daberkow, D. P., Brown, H. D., Bunner, K. D., Kraniotis, S. A., Doellman, M. A., Ragozzino, M. E., et al. (2013). Amphetamine paradoxically augments exocytotic dopamine release and phasic dopamine signals. J. Neurosci. 33, 452-463. doi: 10.1523/JNEUROSCI.2136-1 2.2013

Fendt, M., Schwienbacher, I., and Schnitzler, H. U. (2006). Carbachol injections into the nucleus accumbens induce $50 \mathrm{kHz}$ calls in rats. Neurosci. Lett. 401, 10-15. doi: 10.1016/j.neulet.2006.02.069

Fortin, S. M., Cone, J. J., Ng-Evans, S., McCutcheon, J. E., and Roitman, M. F. (2015). Sampling phasic dopamine signaling with fast-scan cyclic voltammetry in awake, behaving rats. Curr. Protoc. Neurosci. 70, 7. doi: 10.1002/0471142301.ns0725s70

Fu, X. W., and Brudzynski, S. M. (1994). High-frequency ultrasonic vocalization induced by intracerebral glutamate in rats. Pharmacol. Biochem. Behav. 49, 835-841. doi: 10.1016/0091-3057(94)90231-3

Garris, P. A., Ciolkowski, E. L., Pastore, P., and Wightman, R. M. (1994). Efflux of dopamine from the synaptic cleft in the nucleus accumbens of the rat brain. J. Neurosci. 14, 6084-6093.

Garris, P. A., Kilpatrick, M., Bunin, M. A., Michael, D., Walker, Q. D., and Wightman, R. M. (1999). Dissociation of dopamine release in the nucleus accumbens from intracranial self-stimulation. Nature 398, 67-69. doi: $10.1038 / 18019$

Grace, A. A., and Bunney, B. S. (1984). The control of firing pattern in nigral dopamine neurons: single spike firing. J. Neurosci. 4, 2866-2876.

Heien, M. L., Johnson, M. A., and Wightman, R. M. (2004). Resolving neurotransmitters detected by fast-scan cyclic voltammetry. Anal. Chem. 76, 5697-5704. doi: 10.1021/ac0491509

Heien, M. L., Khan, A. S., Ariansen, J. L., Cheer, J. F., Phillips, P. E., Wassum, K. M., et al. (2005). Real-time measurement of dopamine fluctuations after cocaine in the brain of behaving rats. Proc. Natl. Acad. Sci. U.S.A. 102, 10023-10028. doi: 10.1073/pnas.0504657102

Heien, M. L., Phillips, P. E., Stuber, G. D., Seipel, A. T., and Wightman, R. M. (2003). Overoxidation of carbon-fiber microelectrodes enhances dopamine adsorption and increases sensitivity. Analyst 128, 1413-1419. doi: $10.1039 / \mathrm{b} 307024 \mathrm{~g}$

Hori, M., Shimoju, R., Tokunaga, R., Ohkubo, M., Miyabe, S., Ohnishi, J., et al. (2013). Tickling increases dopamine release in the nucleus accumbens and $50 \mathrm{kHz}$ ultrasonic vocalizations in adolescent rats. Neuroreport 24, 241-245. doi: 10.1097/WNR.0b013e32835edbfa

Ikemoto, S. (2010). Brain reward circuitry beyond the mesolimbic dopamine system: a neurobiological theory. Neurosci. Biobehav. Rev. 35, 129-150. doi: 10.1016/j.neubiorev.2010.02.001

Johnson, A. M., Ciucci, M. R., Russell, J. A., Hammer, M. J., and Connor, N. P. (2010). Ultrasonic output from the excised rat larynx. J. Acoust. Soc. Am. 128, EL75-EL79. doi: 10.1121/1.3462234

Kashtelyan, V., Lichtenberg, N. T., Chen, M. L., Cheer, J. F., and Roesch, M. R. (2014). Observation of reward delivery to a conspecific modulates dopamine release in ventral striatum. Curr. Biol. 24, 2564-2568. doi: 10.1016/j.cub.2014.09.016

Kilpatrick, M. R., Rooney, M. B., Michael, D. J., and Wightman, R. M. (2000). Extracellular dopamine dynamics in rat caudate-putamen during experimenter-delivered and intracranial self-stimulation. Neuroscience 96, 697-706. doi: 10.1016/S0306-4522(99)00578-3

Knutson, B., Burgdorf, J., and Panksepp, J. (1998). Anticipation of play elicits highfrequency ultrasonic vocalizations in young rats. J. Comp. Psychol. 112, 65-73. doi: 10.1037/0735-7036.112.1.65

Knutson, B., Burgdorf, J., and Panksepp, J. (2002). Ultrasonic vocalizations as indices of affective states in rats. Psychol. Bull. 128, 961-977. doi: 10.1037/00332909.128.6.961

Kozai, T. D., Li, X., Bodily, L. M., Caparosa, E. M., Zenonos, G. A., Carlisle, D. L., et al. (2014). Effects of caspase-1 knockout on chronic neural recording quality and longevity: insight into cellular and molecular mechanisms of the reactive tissue response. Biomaterials 35, 9620-9634. doi: 10.1016/j.biomaterials.2014.08.006

Kühn, K. U., Meyer, K., and Maier, W. (2000). Flupenthixol- a partial atypical neuroleptic? Fortschr. Neurol. Psychiatr. 68, S38-S41.

Litvin, Y., Blanchard, D. C., and Blanchard, R. J. (2007). Rat $22 \mathrm{kHz}$ ultrasonic vocalizations as alarm cries. Behav. Brain Res. 182, 166-172. doi: 10.1016/j.bbr.2006.11.038

Lórenz-Fonfría, V. A., and Heberle, J. (2014). Channelrhodopsin unchained: structure and mechanism of a light-gated cation channel. Biochim. Biophys. Acta 1837, 626-642. doi: 10.1016/j.bbabio.2013.10.014

Ludvig, E. A., Conover, K., and Shizgal, P. (2007). The effects of reinforcer magnitude on timing in rats. J. Exp. Anal. Behav. 87, 201-218 doi: 10.1901/jeab.2007.38-06

Mahler, S. V., Moorman, D. E., Feltenstein, M. W., Cox, B. M., Ogburn, K. B., Bachar, M., et al. (2013). A rodent "self-report" measure of methamphetamine craving? Rat ultrasonic vocalizations during methamphetamine selfadministration, extinction, and reinstatement. Behav. Brain Res. 236, 78-89. doi: 10.1016/j.bbr.2012.08.023

Manduca, A., Servadio, M., Campolongo, P., Palmery, M., Trabace, L. Vanderschuren, L. J., et al. (2014). Strain- and context-dependent effects of the anandamide hydrolysis inhibitor URB597 on social behavior in rats. Eur. Neuropsychopharmacol. 24, 1337-1348. doi: 10.1016/j.euroneuro.2014.05.009

McCutcheon, J. E., Cone, J. J., Sinon, C. G., Fortin, S. M., Kantak, P. A., Witten, I. B., et al. (2014). Optical suppression of drug-evoked phasic dopamine release. Front. Neural Circuits 8:114. doi: 10.3389/fncir.2014.00114

Melchior, J. R., Ferris, M. J., Stuber, G. D., Riddle, D. R., and Jones, S. R. (2015). Optogenetic versus electrical stimulation of dopamine terminals in the nucleus accumbens reveals local modulation of presynaptic release. J. Neurochem. 134, 833-844. doi: 10.1111/jnc. 13177

Moquin, K. F., and Michael, A. C. (2009). Tonic autoinhibition contributes to the heterogeneity of evoked dopamine release in the rat striatum. J. Neurochem. 110, 1491-1501. doi: 10.1111/j.1471-4159.2009.06254.x

Moussy, F., and Harrison, D. J. (1994). Prevention of the rapid degradation of subcutaneously implanted $\mathrm{Ag} / \mathrm{AgCl}$ reference electrodes using polymer coatings. Anal. Chem. 66, 674-679. doi: 10.1021/ac00077a015

Opiol, H., Pavlovski, I., Michalik, M., and Mistlberger, R. E. (2015). Ultrasonic vocalizations in rats anticipating circadian feeding schedules. Behav. Brain Res. 284, 42-50. doi: 10.1016/j.bbr.2015.02.003

Owesson-White, C. A., Roitman, M. F., Sombers, L. A., Belle, A. M., Keithly, R. B., Peele, J. L., et al. (2012). Sources contributing to the average extracellular concentration of dopamine in the nucleus accumbens. J. Neurochem. 121, 252-262. doi: 10.1111/j.1471-4159.2012.07677.x

Panksepp, J., and Burgdorf, J. (2000). 50-kHz chirping (laughter?) in response to conditioned and unconditioned tickle-induced reward in rats: effects of social housing and genetic variables. Behav. Brain Res. 115, 25-38. doi: 10.1016/S0166-4328(00)00238-2

Panksepp, J., and Burgdorf, J. (2003). "Laughing" rats and the evolutionary antecedents of human joy? Physiol. Behav. 79, 533-547.

Park, J., Aragona, B. J., Kile, B. M., Carelli, R. M., and Wightman, R. M. (2010). In vivo voltammetric monitoring of catecholamine release in subterritories of the nucleus accumbens shell. Neuroscience 169, 132-142. doi: 10.1016/j.neuroscience.2010.04.076

Park, J., Bucher, E. S., Fontillas, K., Owesson-White, C., Ariansen, J. L., Carelli, R. M., et al. (2013). Opposing catecholamine changes in the bed nucleus of the stria terminalis during intracranial self-stimulation and its extinction. Biol. Psychiatry. 74, 69-76. doi: 10.1016/j.biopsych.2012. 11.008

Peters, J. L., Yang, H., and Michael, A. C. (2000). Quantitative aspects of brain microdialysis. Anal. Chim. Acta 412, 1-12. doi: 10.1016/S0003-2670(99) 00839-9

Peterson, G. B. (2004). A day of great illumination: B.F. Skinner's discovery of shaping. J. Exp. Anal. Behav. 82, 317-328. doi: 10.1901/jeab.2004.82-317

Polikov, V. S., Tresco, P. A., and Reichert, W. M. (2005). Response of brain tissue to chronically implanted neural electrodes. J. Neurosci. Methods 148, 1-18. doi: 10.1016/j.jneumeth.2005.08.015

Portfors, C. V. (2007). Types and functions of ultrasonic vocalizations in laboratory rats and mice. J. Am. Assoc. Lab. Anim. Sci. 46, 28-34. 
Ranaldi, R. (2014). Dopamine and reward seeking: the role of ventral tegmental area. Rev. Neurosci. 25, 621-630. doi: 10.1515/revneuro-2014-0019

Redgrave, P., Gurney, K., and Reynolds, J. (2008). What is reinforced by phasic dopamine signals? Brain Res. Rev. 58, 322-339. doi: 10.1016/j.brainresrev.2007.10.007

Reith, M. E., Li, M. Y., and Yan, Q. S. (1997). Extracellular dopamine, norepinephrine, and serotonin in the ventral tegmental area and nucleus accumbens of freely moving rats during intracerebral dialysis following systemic administration of cocaine and other uptake blockers. Psychopharmacology (Berl) 134, 309-317. doi: 10.1007/s002130050454

Roitman, M. F., Stuber, G. D., Phillips, P. E., Wightman, R. M., and Carelli, R. M. (2004). Dopamine operates as a subsecond modulator of food seeking. J. Neurosci. 24, 1265-1271. doi: 10.1523/JNEUROSCI.3823-03.2004

Sadananda, M., Natusch, C., Karrenbauer, B., and Schwarting, R. K. (2012). 50-kHz calls in rats: effects of MDMA and the 5-HT(1A) receptor agonist 8-OH-DPAT. Pharmacol. Biochem. Behav. 101, 258-264. doi: 10.1016/j.pbb.2012.01.012

Scardochio, T., and Clarke, P. B. (2013). Inhibition of $50-\mathrm{kHz}$ ultrasonic vocalizations by dopamine receptor subtype-selective agonists and antagonists in adult rats. Psychopharmacology (Berl) 226, 589-600. doi: 10.1007/s00213012-2931-6

Schultz,W., Dayan, P., and Montague, P. R. (1997). A neural substrate of prediction and reward. Science 275, 1593-1599. doi: 10.1126/science.275.5306.1593

Schwarting, R. K., Jegan, N., and Wöhr, M. (2007). Situational factors, conditions and individual variables which can determine ultrasonic vocalizations in male adult Wistar rats. Behav. Brain Res. 182, 208-222. doi: 10.1016/j.bbr.2007.01.029

Seffer, D., Schwarting, R. K., and Wohr, M. (2014). Pro-social ultrasonic communication in rats: insights from playback studies. J. Neurosci. Methods 234, 73-81. doi: 10.1016/j.jneumeth.2014.01.023

Shu, Z., Taylor, I. M., and Michael, A. C. (2013). The dopamine patchwork of the rat nucleus accumbens core. Eur. J. Neurosci. 38, 3221-3229. doi: 10.1111/ejn.12319

Simola, N., Frau, L., Plumitallo, A., and Morelli, M. (2014). Direct and longlasting effects elicited by repeated drug administration on $50-\mathrm{kHz}$ ultrasonic vocalizations are regulated differently: implications for the study of the affective properties of drugs of abuse. Int. J. Neuropsychopharmacol. 17, 429-441. doi: $10.1017 /$ S1461145713001235

Snoeren, E. M., and Ågmo, A. (2014). The incentive value of males' $50-\mathrm{kHz}$ ultrasonic vocalizations for female rats (Rattus norvegicus). J. Comp. Psychol. 128, 40-55. doi: 10.1037/a0033204

Sparta, D. R., Stamatakis, A. M., Phillips, J. L., Hovelsø, N., van Zessen R., and Stuber, G. D. (2012). Construction of implantable optical fibers for longterm optogenetic manipulation of neural circuits. Nat. Protoc. 7, 12-23. doi: 10.1038/nprot.2011.413

Steinberg, E. E., Boivin, J. R., Saunders, B. T., Witten, I. B., Deisseroth, K., and Janak, P. H. (2014). Positive reinforcement mediated by midbrain dopamine neurons requires D1 and D2 receptor activation in the nucleus accumbens. PLoS ONE 9:e94771. doi: 10.1371/journal.pone.0094771

Steinberg, E. E., Keiflin, R., Boivin, J. R., Witten, I. B., Deisseroth, K., and Janak, P. H. (2013). A causal link between prediction errors, dopamine neurons and learning. Nat. Neurosci. 16, 966-973. doi: 10.1038/nn.3413

Trujillo-Pisanty, I., Sanio, C., Chaudhri, N., and Shizgal, P. (2015). Robust optical fiber patch-cords for in vivo optogenetic experiments in rats. MethodsX 2, 263-271. doi: 10.1016/j.mex.2015.05.003

Tsai, H. C., Zhang, F., Adamantidis, A., Stuber, G. D., Bonci, A., de Lecea, L., et al. (2009). Phasic firing in dopaminergic neurons is sufficient for behavioral conditioning. Science 324, 1080-1084. doi: 10.1126/science. 1168878

Vashist, S. (2013). GFP Antibody. Mater. Methods 3:176. doi: 10.13070/mm.en. 3.176
Wightman, R. M., Amatore, C., Engstrom, R. C., Hale, P. D., Kristensen, E. W., Kuhr, W. G., et al. (1988). Real-time characterization of dopamine overflow and uptake in the rat striatum. Neuroscience 25, 513-523. doi: 10.1016/03064522(88)90255-2

Wightman, R. M., Heien, M. L., Wassum, K. M., Sombers, L. A., Aragona, B. J., Khan, A. S., et al. (2007). Dopamine release is heterogeneous within microenvironments of the rat nucleus accumbens. Eur. J. Neurosci. 26, 2046-2054. doi: 10.1111/j.1460-9568.2007.05772.x

Wightman, R. M., and Robinson, D. L. (2002). Transient changes in mesolimbic dopamine and their association with 'reward'. J. Neurochem. 82, 721-735. doi: 10.1046/j.1471-4159.2002.01005.x

Williams, S. N., and Undieh, A. S. (2010). Brain-derived neurotrophic factor signaling modulates cocaine induction of reward-associated ultrasonic vocalization in rats. J. Pharmacol. Exp. Ther. 332, 463-468. doi: 10.1124/jpet.109.158535

Willuhn, I., Burgeno, L. M., Everitt, B. J., and Phillips, P. E. (2012). Hierarchical recruitment of phasic dopamine signaling in the striatum during the progression of cocaine use. Proc. Natl. Acad. Sci. U.S.A. 109, 20703-20708. doi: 10.1073/pnas.1213460109

Willuhn, I., Tose, A., Wanat, M. J., Hart, A. S., Hollon, N. G., Phillips, P. E., et al. (2014). Phasic dopamine release in the nucleus accumbens in response to prosocial $50 \mathrm{kHz}$ ultrasonic vocalizations in rats. J. Neurosci. 34, 10616-10623. doi: 10.1523/JNEUROSCI.1060-14.2014

Wintink, A. J., and Brudzynski, S. M. (2001). The related roles of dopamine and glutamate in the initiation of $50-\mathrm{kHz}$ ultrasonic calls in adult rats. Pharmacol. Biochem. Behav. 70, 317-323. doi: 10.1016/S0091-3057(01)00615-3

Witten, I. B., Steinberg, E. E., Lee, S. Y., Davidson, T. J., Zalocusky, K. A., Brodsky, M., et al. (2011). Recombinase-driver rat lines: tools, techniques, and optogenetic application to dopamine-mediated reinforcement. Neuron 72, 721-733. doi: 10.1016/j.neuron.2011.10.028

Wöhr, M., Rippberger, H., Schwarting, R. K., and van Gaalen, M. M. (2015). Critical involvement of 5-HT2C receptor function in amphetamine-induced $50-\mathrm{kHz}$ ultrasonic vocalizations in rats. Psychopharmacology (Berl) 232, 1817-1829. doi: 10.1007/s00213-014-3814-9

Wright, J. M., Dobosiewicz, M. R., and Clarke, P. B. (2012). alphaand beta-Adrenergic receptors differentially modulate the emission of spontaneous and amphetamine-induced $50-\mathrm{kHz}$ ultrasonic vocalizations in adult rats. Neuropsychopharmacology 37, 808-821. doi: 10.1038/npp. 2011.258

Wright, J. M., Dobosiewicz, M. R., and Clarke, P. B. (2013). The role of dopaminergic transmission through D1-like and D2-like receptors in amphetamine-induced rat ultrasonic vocalizations. Psychopharmacology 225, 853-868. doi: 10.1007/s00213-012-2871-1

Wright, J. M., Gourdon, J. C., and Clarke, P. B. (2010). Identification of multiple call categories within the rich repertoire of adult rat $50-\mathrm{kHz}$ ultrasonic vocalizations: effects of amphetamine and social context. Psychopharmacology (Berl) 211, 1-13. doi: 10.1007/s00213-010-1859-y

Conflict of Interest Statement: The authors declare that the research was conducted in the absence of any commercial or financial relationships that could be construed as a potential conflict of interest.

Copyright (C) 2015 Scardochio, Trujillo-Pisanty, Conover, Shizgal and Clarke. This is an open-access article distributed under the terms of the Creative Commons Attribution License (CC BY). The use, distribution or reproduction in other forums is permitted, provided the original author(s) or licensor are credited and that the original publication in this journal is cited, in accordance with accepted academic practice. No use, distribution or reproduction is permitted which does not comply with these terms. 